Check for updates

Cite this: RSC Adv., 2017, 7, 34638

\title{
Lignocellulosic fibers: a critical review of the extrusion process for enhancement of the properties of natural fiber composites
}

\begin{abstract}
Antoine Gallos, (D) *ab Gabriel Paës, (DD ${ }^{\text {b }}$ Florent Allais (D) ac and Johnny Beaugrand ${ }^{\text {bd }}$
Natural fiber composites have various applications, since they can bring interesting mechanical and sustainability properties. Extrusion with a single- or twin-screw is the main industrial process to incorporate lignocellulosic fibers into polymers. In this review, the origin and preparation of lignocellulosic fibers are first presented, before discussing the composite processing, with a particular emphasis on the impact of process conditions on the composites final properties that is highly related to the final application. A broad panel of composites reinforced with lignocellulosic fibers is reviewed along with their polymeric matrix, lignocellulosic fiber type and pretreatments, and extrusion process conditions. Finally, the most critical extrusion process parameters (screw profile, speed and temperature) are also examined in order to determine some guidelines to optimize lignocellulosic fiber composites preparation.
\end{abstract}

Received 9th May 2017

Accepted 30th June 2017

DOI: $10.1039 / \mathrm{c} 7 \mathrm{ra0} 240 \mathrm{e}$

rsc.li/rsc-advances

\section{Introduction}

Composites are materials composed of at least two different non-miscible components creating an interface between them. ${ }^{1}$

${ }^{a}$ Chaire Agro-Biotechnologies Industrielles (ABI), AgroParisTech, CEBB, 3 rue des rouges Terres, F-51110 Pomacle, France. E-mail: antoine.gallos@agroparistech.fr

${ }^{b} F A R E$ Laboratory, INRA, Université de Reims Champagne-Ardenne, 2 esplanade Roland-Garros, F-51100 Reims, France

'UMR GMPA, AgroParisTech, INRA, Université Paris-Saclay, Site de Grignon F-78850 Thiverval-Grignon, France

${ }^{d}$ Biopolymères Interactions Assemblages (BIA), INRA, rue de la Géraudière, F-44316 Nantes, France These materials are used worldwide in major industrial sectors like transports and construction. They are usually made of thermoset and thermoplastic polymers reinforced with synthetic fibers and especially glass fibers. Nevertheless, the trends are changing because of numerous factors and real policies supports. Indeed the green economy emergence comes

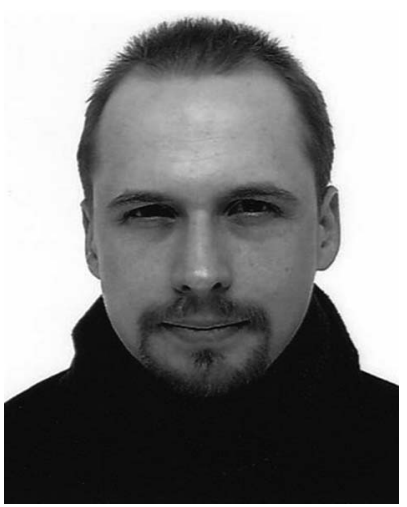

Dr. Antoine Gallos completed his B.S. in chemistry at Université du Littoral Côte d'Opale (ULCO) and his M.S. in material science at Université des Sciences et Technologies de Lille (USTL) in France. He then made a Ph.D on reactive extrusion and flame retardancy of polylactide at École Nationale Supérieure de Chimie de Lille (ENSCL) in the Ingénierie des Systèmes Polymères (ISP) group. After a postdoctoral position dedicated to the study of natural fibers composites, he is now working at the Chaire Agro-Biotechnologies Industrielles by AgroParisTech at the Centre Européen de Biotechnologie et de Bioéconomie (CEBB) as a Research Engineer.

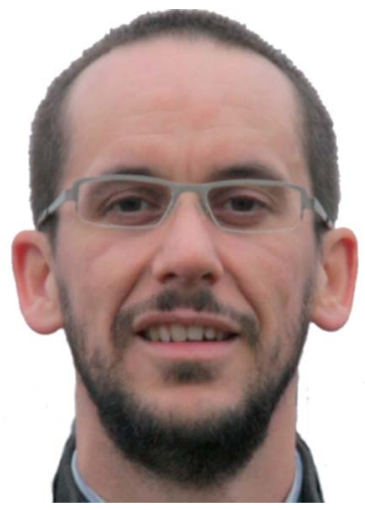

Gabriel Paës is a research scientist working for the French National Institute for Agricultural Research since 2009. Gabriel received his PhD in 2005 and was originally trained in enzyme engineering for optimizing biomass degradation. Then he moved in a private company dedicated to the metabolic engineering of bacteria to produce chemicals. Now his projects are focused on the understanding of the features which control the enzymatic hydrolysis of biomass. To achieve this goal, various biomass plant species and pretreatments are studied by implementing confocal fluorescence techniques (FRAP, FLIM, FRET) to investigate biomass architecture and localisation, interaction and dynamics of probes. 
with new environmental policies established at the state level, or even higher at the international level, as illustrated by the recent guidance for Responsible Agricultural Supply Chains edited by the join Organization for Economic Co-operation and Development (OECD) and Food and Agriculture Organization of the United Nations (FAO). ${ }^{3}$ The green economy promotes natural and renewable resources valorization, reduction of weight or fuel consumption, recyclability or life ending consideration for examples. ${ }^{4}$ In many aspects, markets and needs are evolving quickly. ${ }^{5}$ Research projects follow tendency and bio-based materials became mainstream. To highlight this societal demand, one can mention the European Institute of Innovation and Technology (EIT), where calls for Knowledge and Innovation Communities (KICs) aim, amongst other topics, to build up eco-innovation market replication projects, promoting the area of more sustainable manufacturing in the context of 'the Climate action, environment, resource efficiency and raw materials societal challenges'. ${ }^{6}$ This global wind of change facilitates the development of new composites reinforced with LC fibers (Fig. 1). In this context, private and public funding is rising while publications are piling up (Fig. 2). Life cycle assessment studies also confirm the sustainability of biobased materials and especially LC fibers composite, where LC fibers replace synthetic fibers (e.g., glass fibers, carbon fibers) in industrial applications. ${ }^{7,8}$ As a purpose, this trend would probably continue over the next years according to the forecast of the market (Fig. 3). This is why it is important to investigate and normalize process methods commonly used, in order to ease the production of biocomposites materials reinforced with LC fibers.

LC fibers are mainly composed of bundles containing elementary fibers. The diameter of the bundles is mostly comprised between $5 \mu \mathrm{m}$ and $35 \mu \mathrm{m} .{ }^{9}$ The extrusion process

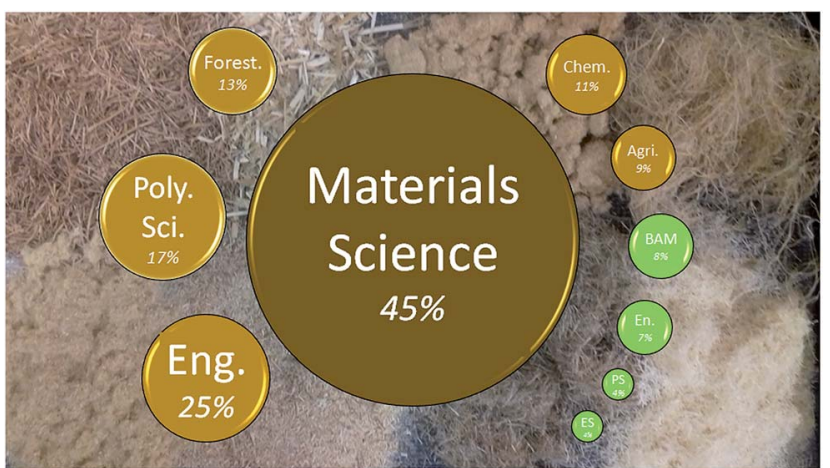

Fig. 1 Relative importance of research areas related to wood and LC fibers. Analysis is based on the query "((wood or lignocellulos*) and (fiber of fibre))" in the topic field on the 2007-2016 time-period performed in the Web of Science (March 2017). Research areas abbreviations are: $\mathrm{Eng}=$ Engineering; Poly. Sci. $=$ Polymer Science; Forest. = Forestry; Chem. $=$ Chemistry; Agri. = Agriculture; BAM = Biotechnology and Applied Microbiology; En. = Energy Fuels; PS = Plant Sciences; $E S=$ Environmental Sciences Ecology. The sum of the percentages is above $100 \%$ since some articles belong to two or more research areas.

frequently causes the shortening of the bundles (e.g., decohesion of elementary fibers, breakage or scission of the whole bundle). ${ }^{10}$ It results a modification of the aspect ratio of the LC fibers impacting the contact surface between the fibers and the polymeric matrix. Aspect ratio is determined by the length of the LC fibers divided by their diameter. The higher the aspect ratio is, the higher the surface contact. Interfaces are ruled by interfacial bonding and are a major concern in composite science since they are the key for stress transfer between the matrix and the LC fibers, determining the mechanical properties of the whole material. ${ }^{11}$ Most of the studies report poor

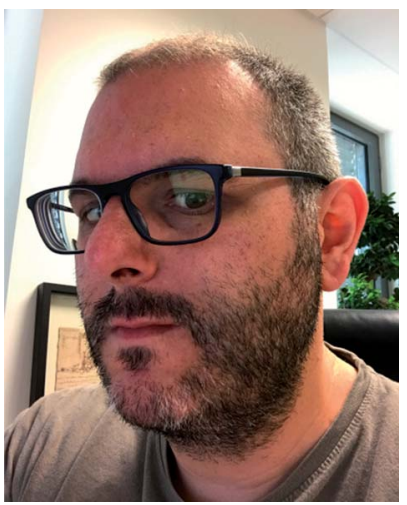

Florent Allais got a PhD in chemistry from the University of Florida (USA) in 2004, then did two postdocs (ESPCI, Paris ICSN-CNRS, Gif-sur-Yvette), before joining the INRA as a Junior Scientist in Versailles (2007). In 2012, he became a Full Professor at AgroParisTech and the director of Chaire $A B I$ at Pomacle. His research is dedicated to the combined use of white biotechnologies, green chemistry and downstream processing for the development and optimization of sustainable industrial processes and high value-added products from biomass. More precisely, his Chair aims at the development of platform molecules that will be used to create valuable sustainable chemicals (e.g., chiral fine chemicals), functional bio-based additives (e.g., anti-UVs, antimicrobials, antiradicals/antioxidants, flavors or surfactants), and polymers/materials.

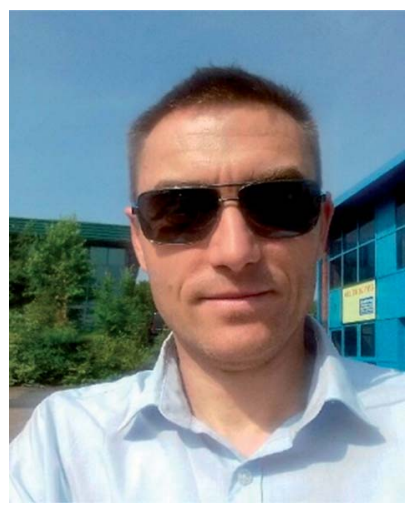

Johnny Beaugrand is a senior scientist working for the French National Institute for Agricultural Research. He recently moved in the city of Nantes (France) after 9 years spent in Reims. After a PhD in plant cell wall biochemistry (2004), he did several postdocs, especially at the KUL. He has managed several research programs. And particularly 'DEFIBREX', founded by the French National Research Agency, about 'optimized DEcohesion of natural FIBeRs during EXtrusion process'. His research concerns lignocellulose breakages, the fibre decohesion and the fragmentation, as 'defibrization'. He is now involved in understanding how physical properties of plant cell walls is modified during various transformation processes (large deformations in mechanics), with a special focus on polymers structures-properties relationships related to fibre fracture incidence. 


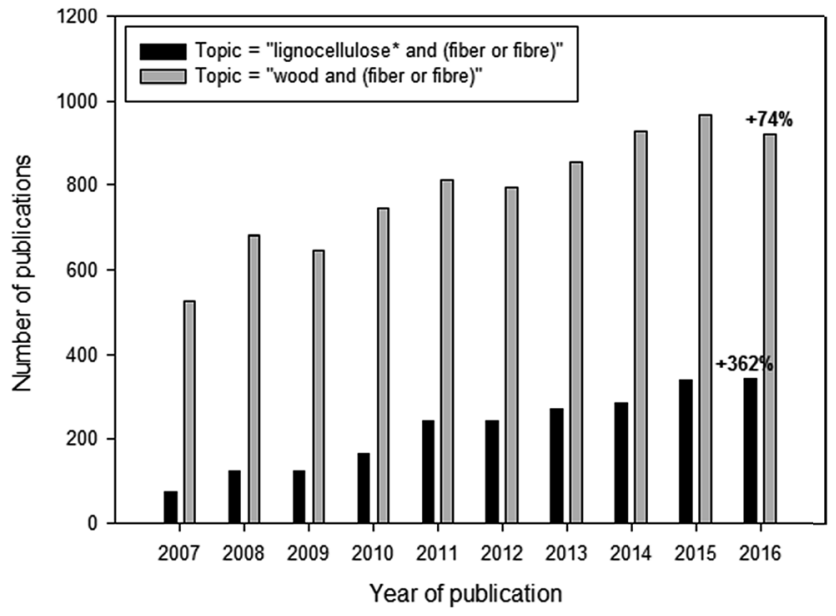

Fig. 2 Number of publications related to the lignocellulosic fibers and wood fibers topics on a 10 year period (2007-2016). Variations of publication number between 2007 and 2016 years are indicated as percentage above the last bar. Results are from queries in the Web of Science (February 2017).

\begin{tabular}{|c|c|c|c|}
\hline Biocomposites & Production in 2012 & $\begin{array}{c}\text { Forecast production } \\
\text { in } 2020 \\
\text { (without incentives for } \\
\text { bio-based products) }\end{array}$ & $\begin{array}{l}\text { Forecast production } \\
\text { in } 2020 \\
\text { (with strong incentives for } \\
\text { bio-based products) }\end{array}$ \\
\hline \multicolumn{4}{|l|}{ WPC } \\
\hline Construction, extrusion & $190,000 \mathrm{t}$ & $400,000 t$ & $450,000 t$ \\
\hline $\begin{array}{l}\text { Automotive, compression moulding \& } \\
\text { extrusion/thermoforming }\end{array}$ & $60,000 \mathrm{t}$ & $80,000 t$ & $300,000 t$ \\
\hline $\begin{array}{l}\text { Technical applications, furniture and } \\
\text { consumer goods, mainly injection } \\
\text { moulding }\end{array}$ & $15,000 \mathrm{t}$ & $100,000 t$ & $>200,000 t$ \\
\hline $\begin{array}{l}\text { Traded granulates for extrusion and } \\
\text { injection moulding }\end{array}$ & $40,000 t$ & $200,000 t$ & $>300,000 t$ \\
\hline \multicolumn{4}{|l|}{ NFC } \\
\hline Automotive, compression moulding & $90,000 \mathrm{t}$ & $120,000 t$ & $350,000 t$ \\
\hline Granulates, injection moulding & $2,000 t$ & $10,000 t$ & $>20,000 t$ \\
\hline
\end{tabular}

Fig. 3 Production of biocomposites (WPC and NFC) in the European Union in 2012 and forecast 2020 (in tons) (reprint with permission from nova 2015 www.bio-based.eu/reports). ${ }^{5}$ interfacial bonding between LC fibers and polymers, leading to the need of a compatibilization of the matrix or a treatment of the LC fibers prior the extrusion process. A recent review has pointed out the importance of the pretreatment and process in the production of nanocomposites reinforced with cellulose. ${ }^{12}$ Even with such pretreatment of the LC fibers, a good interfacial bonding could be hard to achieve since LC fibers tends to absorb moisture and to increase porosity during the process. As it was reported previously, porosity is a factor of great influence for the mechanical properties of a composite. ${ }^{13} \mathrm{We}$ assumed there is a huge impact of the pretreatment and process conditions in the final properties of the thermoplastic composites reinforced with LC fibers. Extrusion is a hot-melt process suitable for continuous processing of composite made of polymer reinforced with LC fibers. It allows to set various parameters (e.g., single or twin-screw, RPM, temperature, residence time) influencing the thermo-mechanical properties of the resulting composite. ${ }^{2}$ This influence is strongly related to the microstructure of the composites (e.g., dispersion of LC fibers, aspect ratio of LC fibers, spatial orientation of LC fibers). ${ }^{14}$

The very wide range of LC fibers (e.g., hemp, flax, kenaf, abaca, bagasse, banana) due to natural biodiversity spread all around the planet, according to soil and climate variations, leads to a huge spectrum of different studies. In addition, the diversity of thermoplastic matrixes, such as polypropylene (PP), polylactide (PLA), polyethylene (PE), polystyrene (PS), polycaprolactone (PCL), multiplies the field of results related to lignocellulosic composites. Due to the amount of multifariousness LC fibers, polymers and pretreatments, added to numerous available extruders coming from many manufacturers that use a lot of different screws (length, diameter, profile) in numerous conditions of temperature and RPM, we have to face a fuzz melting-pot of processes and parametric options (Fig. 4). Laboratory knowledge and empiric experience prevail, but some behavior laws come with the efforts conducted to identify key process parameters or LC fibers traits as

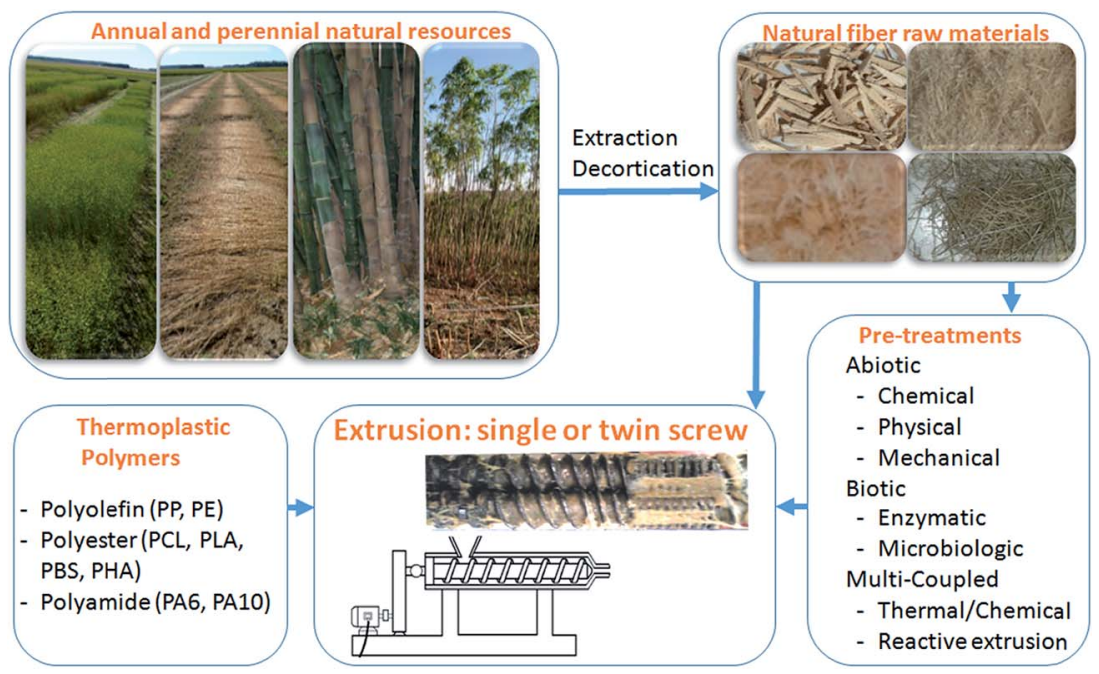

Fig. 4 Synthetical overview of the preparation and extrusion processes of LC fiber composites. 
well as simulations for prediction of LC fibers behavior during compounding.

This review focuses on the investigation of the different single-screw and twin-screw extrusion process methods, and not on the normalization methods and standard of the domain. In an attempt to compare studies and discuss on the impact of the process on the composites properties, the Young's modulus appears to be a representative standard for mechanical properties of composites. ${ }^{15}$ Tensile test and dynamic mechanical analysis are often used for mechanical characterization of composites reinforced with fibers and is widely spread across the world. Stiffness is closely related to the orientation of the fibers in the composites ${ }^{\mathbf{1 6}}$ and have some connections with the efficiency of a given process.

\section{Lignocellulosic fibers}

Lignocellulosic materials are widely spread in the world. Claassen et al. estimated their production at 10-50 billion tons per year (which corresponds to approximately $50 \%$ of the biomass). ${ }^{17}$ The LC fibers are made of cellulose, hemicelluloses, lignin and pectin. The proportion of these products varies from one kind of fiber to another. As a consequence, the LC fibers exhibit diverse mechanical properties. ${ }^{18-21}$ The LC fibers are mostly chosen in accordance with local production and governmental or industrial partnerships. So, the main concern is to valorize the available LC fibers.

\subsection{Grades and sourcing of fibers at the global scale}

There is a huge diversity through the science of biocomposite materials. It seems there is no favored polymer/LC fiber couple. Literature survey shows that the fibers are preferentially selected due to the geographic location. For example hemp fibers are mainly used in composites made in France, ${ }^{2,22-24}$ China, ${ }^{25}$ New Zealand, ${ }^{26-30}$ United States of America, ${ }^{31,32}$ Canada, ${ }^{33}$ Morocco $^{34}$ or even Romania. ${ }^{35}$ Because main hemp producers are located in

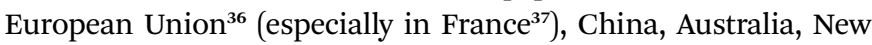
Zealand, Canada and USA. ${ }^{38}$ Many country policies (USA) and sometime at an upper scale, like Common Agricultural Policy in European Union, ${ }^{39}$ are trying to support lignocellulosic crop production. As a result, biocomposite material research mainly follows political and societal trends. Nowadays, the greener seems the better and, despite some controversies with LCA methodologies, some works reported that LC fiber composites seem more ecological than composite reinforced with synthetic fiber, like glass fiber for example. ${ }^{40}$ This is in accordance with the growing amount of scientific articles published during last decade 20072016 (Fig. 2). Even if articles on wood-based fibers are still more numerous than the ones dealing with LC-based fibers (920 vs. 342 publications), the increase over the last decade is clearly in favor of the latter $(+362 \%$ vs. $+74 \%)$, indicating a strong dynamic and interest for LC fibers. In view of the large number of works published in the last decade due to the LC fibers diversity, we chose to mainly focus on two of the most studied LC fibers, hemp and flax fibers. Other LC fibers, such as jute, abaca or sisal, will also be considered as benchmarks.

\subsection{Preparation and pretreatment of fibers}

Due to their close chemical composition, LC fibers exhibit very similar chemical properties, especially on their surface. ${ }^{\mathbf{4 1}}$ Consequently, the encountered issues are mostly a lack of adhesion between the polymers and the fibers. Because of their biochemical composition (polysaccharides in majority), LC fibers are commonly quite hydrophilic. Nevertheless, studies have determined that some differences can be noted from one LC fiber to another. The composition of the fibers can affect some properties like surface energy, ${ }^{41}$ so can their pretreatment. ${ }^{42}$ In fact, prior to their incorporation into polymeric matrixes, LC fibers are often pretreated (Fig. 4 and 5). It exists a lot of different pretreatments done on the fibers before their use. Most of the time, the main goal is to:

(i) Enhance the compatibility between the fibers and the polymeric matrixes (fibers are highly hydrophilic while thermoplastic polymers commonly are hydrophobic).

(ii) Enhance the length/diameter ratio (dispersion and/or defibrillation enhancement) in order to improve the mechanical and/or the thermal properties of the final composite.

Nowadays it is also possible to integrate the eco-conception of the composites and to tailor their life-end, ${ }^{7}$ like recyclable $^{\mathbf{4 3 , 4 4}}$ or compostable abilities. ${ }^{\mathbf{4 5}}$ Some studies also reports works conducted specifically on added functionalities as fire retardancy $^{\mathbf{4 6}}$ or antibacterial ${ }^{\mathbf{4 7}}$ done on LC fiber by pretreatments. The most common pretreatments performed are chemical pretreatments. ${ }^{48-50}$ Others pretreatments could also be physical, $^{23,50}$ biological $^{51}$ or mechanical. ${ }^{52}$ Chemical pretreatments usually focus on fiber surface, where soda (e.g., $\mathrm{NaOH}$ ) or acids (e.g., $\mathrm{HCl}$ ) are often used to "wash" the surface from noncellulosic components. Some of them are also focused on the grafting of molecules (e.g., hydrophilic chains, hydrophobic chains, monomers, polymers) at the surface of the LC fibers. Some chemical pretreatments also focus on the removal of extractives from the woody core ${ }^{53}$ or on the plasticizing of lignins. ${ }^{54}$ There is a huge amount of different pretreatments in various ways like:

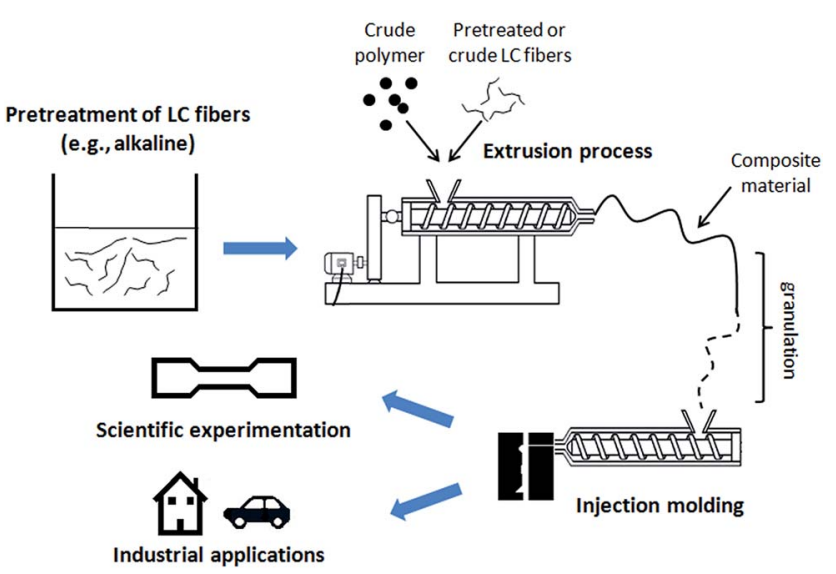

Fig. 5 Pretreatment of LC fibers and their incorporation into a polymeric matrix by extrusion process prior injection molding. 
(i) Chemical (e.g., alkaline, silane, maleic anhydride, acetic anhydride).

(ii) Physical (e.g., irradiation, plasma, corona, thermal).

(iii) Mechanical (e.g., extrusion, carding, cutting).

(iv) Biological (e.g., enzymatic, retting).

(v) A mix of chemical, physical, mechanical or biological pretreatments (e.g., thermal and chemical, ${ }^{55}$ reactive extrusion).

On one hand, LC fibers show a quite good compatibility with hydrophilic polymers such as polyesters (e.g., PLA, PCL). Nevertheless, pretreatment methods are still used on fibers before their incorporation in such polymers in order to enhance the aspect ratio and the final properties of the composites. On the other hand, LC fibers show a weaker cohesion with hydrophobic polymers (e.g., PP or PE). Fiber pretreatments are more important in this case. In numerous studies, coupling agents are directly incorporated into the matrix. For example, maleic anhydride grafted polypropylene (MAPP) is commonly used to enhance the adhesion properties of PP reinforced with LC fibers. ${ }^{56}$ Some works suggest a possible optimal ratio of coupling agent for PP reinforced with LC fibers which can differ for each kind of LC fibers (e.g., flax, hemp, sisal, alfalfa). ${ }^{57,58} \mathrm{~A}$ study conducted by Puglia et al. reports that the compatibilization of the matrix is more effective than that of the fibers in order to improve the final properties of the materials..$^{59}$

Due to their simplicity, alkaline or acidic treatments, which commonly consist in merging the fibers in a $\mathrm{NaOH}$ or $\mathrm{HCl}$ solution for hours, have becoming the most popular fibers pretreatment methods before extrusion (Fig. 5). The goal is to clean the surface from natural and artificial impurities. ${ }^{60}$ This also could be useful to ease the decohesion of fiber elements and to enhance the aspect ratio. Alkaline treatments are well described in the literature..$^{55}$ It is pointed out that an excessive alkaline treatment could remove a significant part of the lignin and damage the fibers. ${ }^{61}$ The cellulose crystallinity may also be modified during a mercerization process and so the properties of the fibers. Such effect of the alkaline treatment depends on the temperature and the concentration of alkalis. ${ }^{62}$

Vandenbossche et al. have described a biomass deconstruction method using alkaline and enzymatic extrusion. ${ }^{63}$ The processes were carried out on a twin-screw extruder, with a screw speed of 85 to $200 \mathrm{RPM}$, in a temperature range going from $40{ }^{\circ} \mathrm{C}$ to $98{ }^{\circ} \mathrm{C}$. This study highlights the influence of the alkaline treatment on the deconstruction of the LC fiber, in accordance with the effects of an excessive alkaline treatment of the fibers. ${ }^{61}$ Moreover, these works emphasize the need to adapt the extrusion process and the pretreatment of the fibers in order to avoid a degradation of the mechanical and thermal properties of the final materials.

\section{Composite processing: fundamentals, structure, formulation, extrusion and properties}

Depicting the whole spectrum of experimental conditions is hard to achieve. The first sub-section presents few basics related to the process of LC fiber composites. Then the structure of the composite and the porosity are also introduced. The third subsection is related to the composites formulations. In this section, some composite formulations and experimental conditions picked up in different studies are reported on Table 1. They are classified according to their polymeric matrixes, their LC fibers (kind, content and dimensions) and their pretreatment before extrusion. The objective is to regroup similar compounds and composites in order to discuss about their structural, thermal or mechanical properties and the formulation or the pretreatment. Then, the fourth section is related to the extrusion of the composites. In this sub-section, Tables 2 and 3 regroup materials by polymeric matrix (PLA, PCL and PP) and detail the conditions of the extrusion processes (single or twin-screw, $L / D$ ratio and temperature profile). This classification will allow us to examine the influence of the process conditions on the material properties. In this review, we focus only on the extrusion process for composite production. We chose to consider the effect of the extrusion process parameters on the mechanical properties (Young's modulus only) measured by tensile test and dynamic mechanical analysis. Finally, the fifth sub-section deals with the general properties of the composite and presents common methods used for the characterization of composites.

\subsection{Basics of lignocellulosic fiber composite processing}

Many processes are in use across the industry of composites (e.g., resin transfer molding, melt mixing, compression molding, pultrusion) ${ }^{64-66}$ Resin infusion is a process commonly designed for thermoset resins where the fibers are directly placed in their final shape in a mold and are impregnated with a monomer mixed with a curing agent. ${ }^{67}$ In some cases, a bag is disposed above the polymer to create a vacuum to avoid the spreading of toxic effluent during the curing. ${ }^{68}$ Melt mixing is more fitted for thermoplastic composites (Fig. 5). The polymer is heated above its melting temperature or at a temperature where its viscosity is sufficiently low to permit a proper flow in case of amorphous thermoplastic. Static mixing can be use to achieve melt blending with a good control of the experimental parameters (e.g., residence time, temperature, shear rate) but in a non-continuous production. ${ }^{69}$ Extrusions involve the same experimental parameters, but they are harder to optimize since this is a continuous process involving a constant flow of mater. Melt mixing implies the use of non-continuous fibers or short fibers. Compression molding can be used to set in shape thermoplastic composites after an extrusion process, like injection molding, or to mold fibers between thermoplastic films ${ }^{70}$ (Fig. 5). It can also be used for impregnated composites molding. ${ }^{71}$ Pultrusion is a process where a continuous fiber is pulled out through an impregnation bath (for thermoset) or a die of an extruder (for thermoplastic). ${ }^{72}$

Across the studies, many different polymeric matrixes are employed to produce composites reinforced with LC fibers. It would be interesting to consider different groups of polymers like polyesters and polyolefins. Polyesters are polymers made of monomers containing at least one ester group, like polylactide (PLA), polycaprolactone (PCL) or polyethylene 
Table 1 Composites reinforced with pretreated LC fibers (without wood-tree resources)

\begin{tabular}{|c|c|c|c|c|c|}
\hline Polymeric matrixes & LC fibers & Initial fiber length (mm) & Pretreatments & Fiber content (wt\%) & References \\
\hline \multirow[t]{9}{*}{ PLA } & \multirow[t]{2}{*}{ Abaca } & Continuous & - & 30 & Bledzki et al. $(2009)^{92}$ \\
\hline & & - & Pre-extrusion & 30 & Bledzki et al. $(2010)^{51}$ \\
\hline & Miscanthus & 1.69 & - & 10 to 40 & Gamon et al. $(2013)^{104}$ \\
\hline & Kenaf & 3 & - & 10 to 30 & Pan et al. $(2007)^{102}$ \\
\hline & Flax & 1 & - & 25.7 & Bourmaud et al. $(2015)^{121}$ \\
\hline & \multirow{4}{*}{ Hemp } & & & & Sawpan et al. $(2011)^{27}$ \\
\hline & & & & & Pickering et al. $(2011)^{28}$ \\
\hline & & & & & Sawpan et al. $(2012)^{29}$ \\
\hline & & 25 & Chemical & 20 to 40 & Oza et al. $(2014)^{31}$ \\
\hline \multirow[t]{25}{*}{ PCL } & Sisal & 1.19 & Chemical (alkaline) & $5-20$ & Carmona et al. $(2014)^{123}$ \\
\hline & Hemp & 14 & - & 20 & Berzin et al. $(2014)^{22}$ \\
\hline & \multirow{9}{*}{ Hemp } & - & Chemical (silane) & 30 & Rachini et al. $(2012)^{24}$ \\
\hline & & - & - & 10 to 40 & Mihai et al. $(2011)^{33}$ \\
\hline & & 1.4 & Chemical (alkaline) & 5 to 30 & Elkhaoulani et al. $(2013)^{34}$ \\
\hline & & 1 to 3 & Chemical (alkaline) & 40 & Beckermann et al. $(2009)^{30}$ \\
\hline & & 2 & Chemical (silane) & 10 to 30 & Panaitescu et al. $(2015)^{106}$ \\
\hline & & 2 to 3 & - & 5 to 10 & Paukszta et al. $(2005)^{125}$ \\
\hline & & 4 to 6 & Chemical & 25 & Iorga et al. $(2013)^{35}$ \\
\hline & & 8 & - & 5 to 30 & Khoathane et al. $(2008)^{105}$ \\
\hline & & 16 to 55 & Chemical (alkaline) & 15 & Bayush et al. $(2012)^{32}$ \\
\hline & Miscanthus & - & Corona & 20 to 40 & Ragoubi et al. $(2012)^{120}$ \\
\hline & \multirow[t]{2}{*}{ Alfa } & 1.3 & Chemical (alkaline) & 5 to 30 & Arrakhiz et al. $(2013)^{126}$ \\
\hline & & 6 to 10 & Chemical (alkaline) & 10 to 30 & El-Abbassi et al. $(2015)^{127}$ \\
\hline & \multirow{2}{*}{ Flax } & 2 to 3 & - & 5 to 10 & Paukszta et al. $(2005)^{125}$ \\
\hline & & 4.5 & Chemical (alkaline) & 5 to 50 & El-Sabbagh et al. $(2013)^{132}$ \\
\hline & Pine cone & 0.5 & Chemical (alkaline) & 5 to 30 & Arrakhiz et al. $(2012)^{133}$ \\
\hline & \multirow{4}{*}{ Jute } & - & - & 10 to 30 & Doan et al. $(2006)^{134}$ \\
\hline & & - & Chemical (alkaline) & 10 & Marques et al. $(2015)^{129}$ \\
\hline & & 2 & - & 40 & Bledzki et al. $(2015)^{124}$ \\
\hline & & 3 & Chemical & 20 to 35 & Kabir et al. $(2010)^{135}$ \\
\hline & \multirow[t]{2}{*}{ Curaua } & - & Chemical (alkaline) & 10 & Marques et al. $(2015)^{129}$ \\
\hline & & 3 to 7 & - & 20 & Mano et al. $(2010)^{136}$ \\
\hline & Sisal & 10 & Chemical (alkaline) & 10 to 30 & Pimenta et al. $(2008)^{137}$ \\
\hline & Kenaf & 2 & - & 40 & Bledzki et al. $(2015)^{124}$ \\
\hline
\end{tabular}

terephthalate (PET). PLA is synthesized from renewable resources while it is industrially compostable or recyclable. ${ }^{73}$ PCL is made of fossil resources and is fully biodegradable. PBS offers a good compromise between technical performance, fiber adhesion and recyclability. ${ }^{43}$ Polyethylene terephthalate, which is a polyester traditionally made of fossil resources, tends to become greener since various studies talk about biobased PET. ${ }^{19}$ In all cases, it is well known for its recyclability and/or reusability. Most of the time, polyesters are hydrophilic polymers and exhibit quite good compatibility with LC fibers that are also hydrophilic. Polyolefins are usually polymers made of carbon-hydrogen aliphatic chains coming from the polymerization of alkene monomers. Polypropylene (PP), high density polyethylene (HDPE) and low density polyethylene (LDPE) are the most common polyolefins used in industry and are mainly recyclable. ${ }^{74-77}$ Due to their chemical structure, polyolefins are hydrophobic. They are uneasy to mix with LC fibers and a pretreatment or a compatibilization process is highly recommended. In this review, we chose to only consider PP, PCL and PLA because they are very common and there are 
Table 2 Process conditions in PLA and PCL reinforced with LC fibers

\begin{tabular}{|c|c|c|c|c|c|c|c|c|}
\hline Screw & $L / D$ & $D(\mathrm{~mm})$ & RPM & $\begin{array}{l}\text { Temperature } \\
\text { profile }\left({ }^{\circ} \mathrm{C}\right)\end{array}$ & $\begin{array}{l}\text { Process } \\
\text { (qualitatively) }\end{array}$ & Fibers & $\begin{array}{l}\text { Young's } \\
\text { modulus (GPa) }\end{array}$ & References \\
\hline \multicolumn{9}{|l|}{ PLA } \\
\hline \multirow[t]{6}{*}{ Single } & - & - & 20 & $175-185$ & Soft & Flax & - & Bourmaud et al. $(2010)^{122}$ \\
\hline & - & - & 20 & 190 & Soft & Flax & $3.8-7.4$ & Bourmaud et al. $(2015)^{121}$ \\
\hline & - & - & 63 & $175-200$ & Soft & Miscanthus & $2.4-3.2$ & Ragoubi et al. $(2012)^{120}$ \\
\hline & - & - & 80 & 200 & Soft & Kenaf & $1.4-1.9$ & Pan et al. $(2007)^{102}$ \\
\hline & - & 19 & 8 & 175 & Soft & Hemp & - & Oza et al. $(2014)^{31}$ \\
\hline & 25 & 30 & 20 & 180 & Soft & Abaca & $3.3-8.0$ & Bledzki et al. (2009) $)^{92}$ \\
\hline \multirow[t]{7}{*}{ Twin } & 25 & 15 & 100 & $175-190$ & Severe & Hemp & $3.5-8.2$ & Sawpan et al. $(2011)^{26}$ \\
\hline & & & & & & & - & Sawpan et al. $(2011)^{27}$ \\
\hline & & & & & & & - & Pickering et al. $(2011)^{28}$ \\
\hline & & & & & & & - & Sawpan et al. $(2012)^{29}$ \\
\hline & 32 & 25 & 100 & 200 & Severe & Abaca & $3.3-8.0$ & Bledzki et al. $(2010)^{100}$ \\
\hline & 32 & 25 & 100 & 200 & Severe & Jute & $3.4-9.6$ & Bledzki et al. $(2010)^{100}$ \\
\hline & 44 & 28 & $100-300$ & $165-190$ & Severe & Miscanthus & $6.0-6.4$ & Gamon et al. $(2013)^{104}$ \\
\hline \multicolumn{9}{|l|}{ PCL } \\
\hline \multirow[t]{3}{*}{ Twin } & - & 18 & 200 & $140-160$ & Severe & Sisal & - & Carmona et al. $(2014)^{123}$ \\
\hline & 36 & 25 & $100-300$ & 100 & Severe & Hemp & - & Berzin et al. $(2014)^{22}$ \\
\hline & 36 & 25 & $100-400$ & $100-140$ & Severe & Hemp & $0.1-0.3$ & Beaugrand et al. $(2013)^{2}$ \\
\hline
\end{tabular}

Table 3 Process conditions in PP reinforced with LC fibers

\begin{tabular}{|c|c|c|c|c|c|c|c|c|}
\hline Screw & $L / D$ & $D(\mathrm{~mm})$ & RPM & $\begin{array}{l}\text { Temperature } \\
\text { profile }\left({ }^{\circ} \mathrm{C}\right)\end{array}$ & $\begin{array}{l}\text { Process } \\
\text { (qualitatively) }\end{array}$ & Fibers & $\begin{array}{l}\text { Young's } \\
\text { modulus (GPa) }\end{array}$ & References \\
\hline \multirow[t]{13}{*}{ Single } & 25 & 30 & 20 & 180 & Soft & Abaca & $1.5-4.9$ & Bledzki et al. (2009) ${ }^{92}$ \\
\hline & - & - & 28 & $175-190$ & Soft & Alfa & $1.4-3.6$ & El-Abbassi et al. $(2015)^{127}$ \\
\hline & 25 & 30 & - & - & Soft & Jute & $1.5-5.8$ & Bledzki et al. $(2010)^{100}$ \\
\hline & - & - & - & 160 & - & Jute & $1.0-3.5$ & Kabir et al. $(2010)^{135}$ \\
\hline & - & - & 60 & $165-170$ & Soft & Hemp & $1.2-4.3$ & Khoathane et al. $(2008)^{105}$ \\
\hline & - & - & 63 & $175-200$ & Soft & Hemp & $0.7-1.2$ & Ragoubi et al. $(2010)^{23}$ \\
\hline & 25 & 25 & 30 & $140-200$ & Soft & Hemp & - & Paukszta et al. $(2005)^{125}$ \\
\hline & - & - & 63 & $175-200$ & Moderate & Miscanthus & $0.8-1.5$ & Ragoubi et al. $(2012)^{120}$ \\
\hline & - & - & 20 & 190 & Soft & Flax & $1.8-5.8$ & Bourmaud et al. $(2015)^{121}$ \\
\hline & 11 & 46 & - & $180-210$ & - & Flax & $1.6-3.7$ & Doumbia et al. $(2015)^{131}$ \\
\hline & 25 & 25 & 30 & $140-200$ & Soft & Flax & - & Paukszta et al. $(2005)^{125}$ \\
\hline & 30 & 20 & 20 & 190 & Soft & Flax & $1.8-7.4$ & Ausias et al. $(2013)^{130}$ \\
\hline & - & 25 & 50 & $175-185$ & Soft & Sisal & $0.9-1.7$ & Pimenta et al. $(2008)^{137}$ \\
\hline \multirow[t]{21}{*}{ Twin } & 23 & 34 & 40 & $170-200$ & Moderate & Abaca & - & Bledzki et al. $(2015)^{124}$ \\
\hline & - & - & - & $165-193$ & - & Jute & $1.5-4.3$ & Doan et al. $(2006)^{134}$ \\
\hline & - & - & 60 & 180 & Moderate & Jute & - & Marques et al. $(2015)^{129}$ \\
\hline & 23 & 34 & 40 & $170-200$ & Moderate & Jute & - & Bledzki et al. $(2015)^{124}$ \\
\hline & - & - & 40 & $190-215$ & Severe & Hemp & $1.8-4.0$ & Iorga et al. $(2013)^{35}$ \\
\hline & - & - & 120 & $160-170$ & Severe & Hemp & $0.9-2.1$ & Panaitescu et al. $(2015)^{106}$ \\
\hline & - & - & 125 & $180-200$ & Severe & Hemp & $1.0-1.8$ & Elkhaoulani et al. $(2013)^{34}$ \\
\hline & - & 18 & 40 & $180-200$ & Moderate & Pine cone & $1.0-1.6$ & Arrakhiz et al. $(2012)^{133}$ \\
\hline & - & 18 & 80 & 185 & Moderate & Hemp & $0.9-1.2$ & Bayush et al. $(2012)^{32}$ \\
\hline & - & 18 & 125 & $180-200$ & Severe & Alfa & $0.9-1.6$ & Arrakhiz et al. $(2013)^{126}$ \\
\hline & - & 18 & 125 & $180-200$ & Severe & Coir & $0.9-1.5$ & Arrakhiz et al. $(2013)^{126}$ \\
\hline & - & 18 & 125 & $180-200$ & Severe & Bagasse & $0.9-1.5$ & Arrakhiz et al. $(2013)^{126}$ \\
\hline & - & 33 & 400 & $160-170$ & Severe & Hemp & 5.0 & Rachini et al. $(2012)^{24}$ \\
\hline & - & - & 30 & 180-185 & Moderate & Flax & - & Retegi et al. $(2006)^{128}$ \\
\hline & - & - & 60 & 180 & Moderate & Flax & - & Marques et al. $(2015)^{129}$ \\
\hline & 38 & 25 & $100-200$ & $180-200$ & Severe & Flax & $0.7-1.6$ & El-Sabbagh et al. $(2014)^{57}$ \\
\hline & 40 & 18 & - & $170-200$ & - & Flax & $1.4-3.5$ & Doumbia et al. $(2015)^{131}$ \\
\hline & 40 & 34 & $100-200$ & $175-200$ & Severe & Flax & $1.3-5.0$ & Mihai et al. $(2011)^{33}$ \\
\hline & - & - & 60 & 180 & Moderate & Curaua & - & Marques et al. $(2015)^{129}$ \\
\hline & - & 44 & $250-500$ & $160-180$ & Severe & Curaua & $1.9-3.4$ & Mano et al. $(2010)^{136}$ \\
\hline & 23 & 34 & 40 & $170-200$ & Moderate & Kenaf & - & Bledzki et al. $(2015)^{124}$ \\
\hline
\end{tabular}


also a lot of studies using very different processes with these polymers.

\subsection{Structure and porosity}

During the process, some air (or nitrogen if the process occurs under nitrogen flow), water vapor or volatile organic compound (VOC) can be trapped in the composite. Most of the time, those gases may create some cavities between the LC fibers and the matrix. It is called porosity. As described by Madsen et al.,${ }^{13}$ the porosity strongly depends on the quantity of fibers incorporated and on the process used. A high fiber load (e.g., superior to 60 $\mathrm{wt} \%$ of hemp fibers in a PP matrix $)^{13}$ could lead to a sharp increase of porosity due to fiber aggregates. An incomplete compaction of the fibers during the process can also increase the porosity. However, the porosity created during the process could occur at every fiber content since it directly results from the mixing of two different materials. As a consequence, the experimental conditions of the process are very determining for the final mechanical properties of the composites and especially for composites reinforced with LC fibers, because it can cause both fibers degradation (thermal or mechanical degradations) and porosity. ${ }^{78}$ As a significant part of the porosity induced by the process is located at the interface between the fibers and the matrix, it is quite logic to consider the chemical affinities between the fibers and the matrix because it could affect the amount of porosity created during the process. This is why the fiber pretreatments are also considered in addition to the fiber rates and to the process conditions in Table 1.

The pretreatment of LC fibers and the removal of water (before or during the process) are not the only ways to reduce the porosity in the final material. Some works conducted in our laboratory highlighted a possible decrease of the porosity after an injection process, as illustrated on Fig. 6. The preparation of the samples and the process are described elsewhere. ${ }^{2}$ On one hand, structure and porosity of composites are strongly related to the mechanical properties of the final materials. On the second hand, the process has a significant influence on the structure and on the porosity (even extrusion parameters and fibers preparation). As

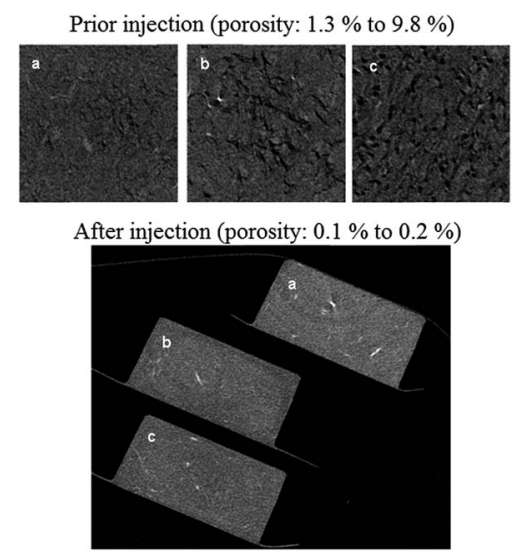

Fig. 6 Possible decrease of the porosity in polycaprolactone reinforced with natural hemp fibers after an injection process (porosity measured by scanning electron microscopy and image analysis). a consequence, knowing the effect of the process parameters on the structure and on the porosity of the composite helps to improve the final properties of the materials.

A very similar statement can be done with the microstructure of the composites reinforced with LC fibers. The microstructure concerns the orientation, the dispersion and the distribution of the fibers. It is highly connected to the properties of the material and the process can affect microstructure parameters, like aspect ratio or fiber dispersion..$^{59,79}$ As a result, the microstructure is strongly linked to the final properties of the material. As reported in some of our previous works, the characterization of the microstructure can be conducted from nanoscale to macroscale with a large broad of different techniques (e.g., Transmission Electron Microscopy (TEM), Scanning Electron Microscopy (SEM), micro X-ray Computed Tomography (X-ray CT), Confocal Laser Scanning Microscopy (CLSM), Confocal Raman Imaging (CRI)) and, often the time, the imaging techniques require an accurate image analysis, especially to investigate and to understand the relations between the microstructure and the material properties. ${ }^{14}$

\subsection{Formulation of composites}

This review has considered 39 publications listed hereafter in the Table 1, mentioning the use of LC fibers and extrusion process during the last 15 years (from 2002 to 2016). Our selection is based on the choice of the most boosted research of the works conducted on some polymers (PP, PLA and PCL) reinforced with LC fibers throughout extrusion process. We chose to firstly classify these materials in three categories corresponding to polymeric matrixes. Then we collected the information about the kind, rates and lengths of fibers used. We also added the pretreatments done on these fibers. Industrial composites often the time require the addition of antioxidant additives to ensure their durability. ${ }^{80}$ Due to the relatively low amount of such additives used in the final compounds, we think they have no significant effect on the process and we willingly chose to neglect them in this review.

Except one study where continuous fiber is used, the fiber length is comprised between $0.5 \mathrm{~mm}$ and $55 \mathrm{~mm}$. Regrettably, a third of the studies does not indicate the initial fiber length. Fibers shorter than $10 \mathrm{~mm}$ are commonly used in thermoplastic composite, while fiber longer than $10 \mathrm{~mm}$ are less reported. Extrusion process often the time breaks and shortens the long fibers due to friction strength, as it was reported and described in many works. ${ }^{2,22,32,81}$ Long fibers are also known to be difficult to introduce in the extruder and to increase the viscosity or create huge blockage in the die. Because it is very hard to preserve the initial length of long fibers during an extrusion process and because it is easier to feed the extruder at a constant rate with short fibers, the infra $10 \mathrm{~mm}$ granulometry length is mostly preferred. Moreover, in an economic point of view, the longer LC fiber raw material are generally more costly than the second fiber grade 'tow', reinforcing the use of relatively short LC fiber in extrusion. Different ways of fiber pretreatments are used. The chemical pretreatments (e.g., alkaline, silane, maleic anhydride, acetic anhydride) are the 
most common in all polymeric matrixes. Nevertheless, there are some others ways, like physical pretreatment with some preextrusion method or corona techniques. The selection of the pretreatment process seems to be independent of the nature and of the loading rate of the LC fibers.

Considering the whole composites, the feeding rate goes from $5 \mathrm{w} \%$ to $50 \mathrm{wt} \%$. In almost $60 \%$ of these studies, the fiber content is exclusively comprised between $20 \mathrm{wt} \%$ and $40 \mathrm{wt} \%$. It can also be noted that $90 \%$ of these studies have at least one sample with a fiber content within this range. This is in accordance with some examples of composites used in common industrial applications, like transportation..$^{82}$ Some works have shown an increase of the mechanical properties of the LC fiber reinforced composites when the fiber content goes up to $50 \mathrm{wt} \%$ where they reach a maximum value. ${ }^{83}$ This is in accordance with the works of Madsen et al. discussed previously where the porosity sharply increases after $60 \mathrm{wt} \%$ of fiber content. ${ }^{13} \mathrm{An}$ increase of the concentration of the fibers can enhance the aspect ratio, due to fiber entanglement, as reported by Puglia et al. ${ }^{59} \mathrm{~A}$ statistical study conducted by Le Moigne et al. on sisal, flax and wheat straw fibers incorporated in a PP, with maleic acid used as compatibilizer, showed no influence of the fiber concentration on the aspect ratio of the fibers from $20 \mathrm{wt} \%$ to 40 wt $\% .^{9}$ They used a batch kneader (and not an extruder) to conduct this study, but on the basis of the works led by Bos et al. ${ }^{84}$ they claimed that using a kneader instead of an extruder would lead to similar size and shape distribution of the fibers.

\subsection{Extrusion of composites}

There are a lot of manufacturers working at the size of a country, or international firms such as Brabender, Clextral, Coperion, Leistriz, Werner \& Pfleiderer, K-Tron, Xinda or ThermoFisher for some examples, who equip research laboratories up to factory all around the world. Such diversity could be explained by the large scope of applications for extrusion processes. It is often used in food industry, pharmacology and plastic manufacture because it offers a high amount of benefits like being a solvent-free non ambient process with a reduced production time. ${ }^{85}$ Hot melt extrusion is the major process used to manufacture plastic across the world. ${ }^{86}$ As the plastic market skyrocket during the last century and with the emergence of the bioplastic industry since many years, it sounds logic to have heavy investments from manufacturers in order to fit with all of the applications. In composite science, and especially in the case of composite reinforced with LC fibers, a lot of works were carried out on single-screw or twin-screw extruders, each one with its own screw profile and temperature profile, each one with different screw speed and residence time. It is possible to find a very large spectrum of experimental conditions for the same LC fiber mixed with the same polymer, in order to produce the same compound. Fig. 7 and 8 respectively represent a single screw extruder and a twin-screw extruder.

This part will quickly present the processes used to compound composites materials. As we aim at determining the influence of condition process on thermal and mechanical properties of the lignocellulosic reinforced polymeric composites, we chose to consider a representative part of the experimental conditions exposed in several studies from 2002 to 2016. Hereafter are listed these process conditions in different matrixes like PLA, PCL and PP (Tables 2 and 3). Those matrix were selected because PP is the most used matrix associated with LC fibers, PLA is one of the most published biobased polymer and has a process temperature close to PP, and PCL because of its assumed good compatibility with hydrophilic load bearing LC fibers.

As described previously, the process plays a critical role in the final properties of the composites since it is directly related to the porosity of the final material and may preserve or not the polymer. ${ }^{65}$ Moreover, the process can also causes some damages to the fiber bundles and so the morphometry of the solid phase.

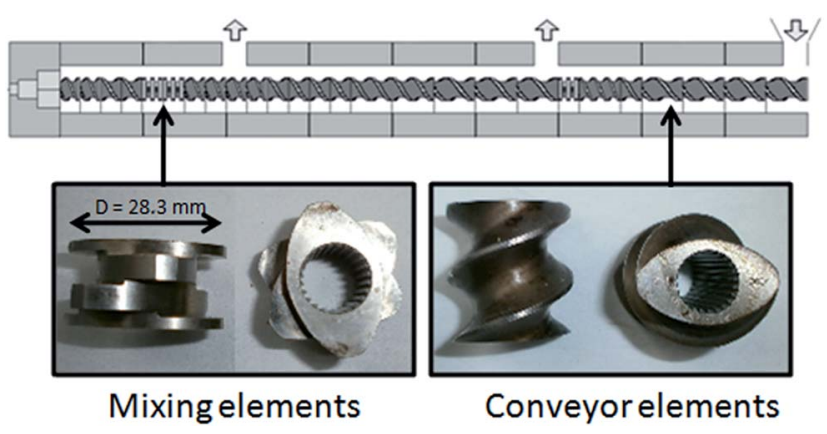

Fig. 8 Scheme of a twin-screw extruder profile generated by Ludovic ${ }^{\circledR}$ and pictures of screw elements.
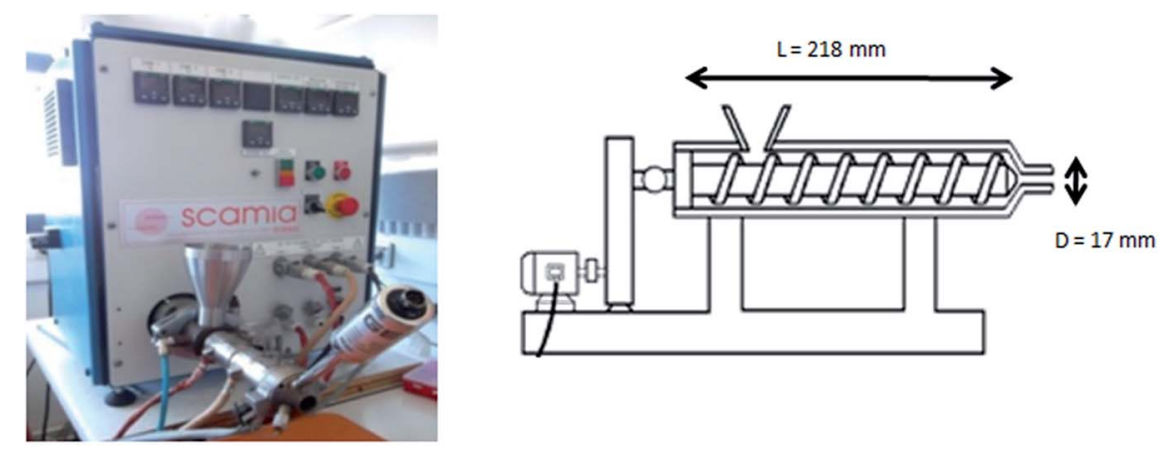

Fig. 7 Representation of a single-screw extruder. 
A high mechanical energy provided by the screw profile and speed or a high temperature can enhance the aspect ratio and lead to composites with improved mechanical properties. But it can also result in composites with reduced mechanical properties due to increased porosity or degraded fiber bundles. A study led on wood polymer composites demonstrated the influence of process parameters (e.g., screw design, temperature, RPM) on the size of the particles in the final material. ${ }^{87}$ As reported by Hanawalt, ${ }^{88}$ the temperature of the process should be set in accordance with the thermal stability of the fiber in order to prevent thermal degradation. Such degradations would certainly cause some flaws into the fiber bundles and decrease the mechanical properties. With such consideration, it is important to correctly define the process parameters in order to optimize the aspect ratio of the fibers while limiting as much as possible the damages to the fibers. The balance between a good dispersion of the fibers in the matrix obtained with significant cumulative strain or SME in part, and in other part the preservation of the reinforcement characteristics (e.g., length, aspect ratio), is difficult because antagonistic. Works described the decrease of the stiffness of LC fibers due to high stress. ${ }^{89}$

Moreover, Cisneros et al. have demonstrated that a too high screw speed could trap some air in the material during the twinscrew extrusion of amylopectin. ${ }^{90}$ It is consistent with our own study (Fig. 6). ${ }^{2}$ It can be assumed that such phenomenon could also occur during extrusion process for composite compounding. This would also lead to a decrease of the mechanical properties of the final material. The best way to investigate the effect of the mechanical strength applied to the fiber during the extrusion process is to determine the SME. ${ }^{2}$ It is related to the mass flow rate of compound, to the motor power of the extruder, to the torque and to the RPM of the screws. ${ }^{91}$ Unfortunately, due to a lack of information about the motor power and torque of the extruder used throughout the works described in literature, it was not possible to calculate or estimate the SME in this review. So the only way to investigate the severity of the process found in literature is to qualitatively discuss about the RPM and the temperature. We chose to classify processes in three categories: soft, moderate and severe. "Soft" is for single screw process under 100 RPM and with a maximum temperature not higher than $200{ }^{\circ} \mathrm{C}$. "Moderate" is for twin screw process under 100 RPM and with a maximum temperature not exceeding $200{ }^{\circ} \mathrm{C}$. "Severe" is for the others processes with a higher setup in one consign or in combination.

Single screw profiles are more used than twin screw for PLA. Although there are some analogies with the length (up to $800 \mathrm{~mm}$ ) and diameter (up to $30 \mathrm{~mm}$ ) of the screws used, the rotation speed exhibits some differences from one study to another. The RPM is comprised between 8 and 300. This information allows to estimate the residence time in the extruder. For example, the processing of composites at 100 RPM in a single screw with a length of $390 \mathrm{~mm}^{26-29}$ is quicker than in a single $750 \mathrm{~mm}$ long screw extruder at 20 RPM. ${ }^{92}$ The temperature profile is also an important parameter because it determines the viscosity of the polymeric matrix. Often the time, the extruders design allow to set different temperatures at different stage of the profile. We choose to focus on the minimum and the maximum temperatures of each of these profiles where the temperatures were set from $175{ }^{\circ} \mathrm{C}$ to $200{ }^{\circ} \mathrm{C}$.

Few studies have been found on PCL reinforced with LC fibers throughout an extrusion process. They involve twin-screw extruders, relatively high RPM (between 100 and 400) and various temperature range from $100{ }^{\circ} \mathrm{C}$ to $160^{\circ} \mathrm{C}$.

At the laboratory scale, excluding pilot and industrial scales, many works have been conducted both with single screw and twin-screw extruders for PP composites. The dimensions of the screw exhibit a wide diversity, where the diameter goes from 18 $\mathrm{mm}$ to $34 \mathrm{~mm}$ and the length reaches $1360 \mathrm{~mm}$. The rotation speed of the screws also varies a lot from one study to another (40 to $200 \mathrm{RPM}$ ). The temperature profiles were set between $160{ }^{\circ} \mathrm{C}$ and $200{ }^{\circ} \mathrm{C}$.

\subsection{Properties of composites}

To match industrial applications (e.g., transport, construction sectors), such composite materials obviously have to fulfill numerous thermo-mechanical given properties that are dependent on the polymeric matrix, the LC fibers and the interactions between these components. As described previously, the interface between the LC fibers and the polymers can dramatically affect the mechanical properties of the resulting material. The nature of the polymeric matrix plays a huge role on the final properties of the composites and will determine its applications. Polymers have their own chemical resistance (e.g., to acids, bases, solvents), thermo-mechanical properties, fire resistance or aging behavior. The incorporation of LC fibers could improve some properties (e.g., mechanical properties), without affecting others properties (e.g., solvent resistance), while decreasing various properties in some ways (e.g., fire resistance). The science of composite materials requires reliable and comprehensive characterizations to lead to sustainable applications.

Even if the importance of other properties should not be underestimated, the mechanical properties are probably the most important features to characterize materials reinforced with LC fibers. Mechanical properties are commonly determined by tensile tests (ISO 527, ASTM D638) to determine the module of elasticity (Young's modulus), the tensile strength and the elongation at break. Other methods, like Dynamic Mechanical Analysis (DMA) are also used to determine complex Young's modulus. Composites can also be characterized according to their resistance to impact with an izod impact test (ISO 180, ASTM D256). Industrial applications sometime require specific characterizations like Shore hardness (ASTM D2240). The most common methods used to study the thermal properties of the composites are the Thermo-Gravimetric Analysis (TGA) and the Differential Scanning Calorimetry (DSC). TGA is most of the time used to characterize the thermal stability of materials by measuring the weight loss according to the temperature under controlled atmosphere (e.g., oxidative atmosphere, inert atmosphere with pure $\mathrm{N}_{2}$ or $\mathrm{Ar}$ ). TGA can also evidence synergistic or antagonistic effects on thermal stability between the components of a composite material. ${ }^{93}$ DSC is mostly employed for the characterization of glass transition 
temperature $\left(T_{\mathrm{g}}\right)$, the quantification of melting or crystallization enthalpies $\left(\Delta H_{\mathrm{m}}\right.$ and $\left.\Delta H_{\mathrm{c}}\right)$ and temperatures $\left(T_{\mathrm{m}}\right.$ and $\left.T_{\mathrm{c}}\right)$, or the determination of the heat capacity at constant pressure $\left(C_{\mathrm{p}}\right)$. Such properties of thermoplastic polymeric matrixes can be impacted by the addition of LC fibers or other natural fillers. ${ }^{\mathbf{9 4 , 9 5}}$ Fire retardancy topic abounds of testing methods to characterize the composite materials. ${ }^{96}$ Flammability tests, like UL-94 (ISO 1210, ASTM D3801) and limiting oxygen index (ISO 4589-2, ASTM D2863), or heat release tests, like cone calorimeter (ISO 5660, ASTM E1354) or pyrolysis combustion flow calorimetry, are commonly used. All of these tests, sometimes in combination with modeling calculation, aim to improve fire resistance of composite materials and insure fire safety in industrial applications. ${ }^{97}$ The aging study of composite materials consists in reproducing environmental or harsh conditions, ${ }^{98,99}$ before reproducing thermo-mechanical characterization described previously. Such studies are sometimes pertinent to investigate the sustainability of the LC fiber composites. In this review, we have chosen to focus on the influence of the extrusion process on the mechanical properties related to the Young's modulus of composite materials reinforced with LC fibers.

\section{Impact of the process on Young's modulus}

In this part, the following discussions aim to make some comparisons between the process and the mechanical properties of the materials. As described previously and reported in Tables 2 and 3, the processes are qualitatively classified in three categories (soft, moderate and severe) corresponding to an estimation of the severity of the process.

\subsection{PLA composites}

There have been different works conducted on PLA reinforced with hemp fibers exhibiting various processes. Unfortunately, the mechanical properties were not investigated in all of these studies. So, to get an enlarged set of data we also considered PLA reinforced with abaca and kenaf fibers in order to make some comparisons between the Young's modulus of the final materials and to investigate the impact of the process conditions.

Bledzki et al. have processed PLA with $30 \mathrm{wt} \%$ abaca fibers to prepare a composite exhibiting a Young modulus of $8.0 \mathrm{GPa}$ throughout a succession of two processes..$^{\mathbf{9 2 , 1 0 0}}$ The first one is severe but it is only used to melt the polymers and the incorporation of an abaca monofilament occurs in a coating die at the end of the extruder, and the composite is pelletized. This process is used for a soft incorporation into the polymeric matrix. The second process is soft and used to mix the composite pellets in order to achieve a better dispersion of the fibers in the matrix. In their study, Sawpan et al. made a PLA composite filled with $30 \mathrm{wt} \%$ of abaca fibers with a Young's modulus of $8.2 \mathrm{GPa}^{26}$ Prior extrusion, the fibers were compatibilized via an alkaline pretreatment. Then the composite is made after a severe process. Without any compatibilization but with the same extrusion process, the same kind of material shows a Young's modulus of 7.5 GPa. Sawpan et al. explain this difference by a better surface adhesion between the fibers and the matrix reached by the compatibilization of the fibers with the alkaline pretreatment. So, if we compare the two PLA filled with $30 \mathrm{wt} \%$ of chemically-untreated-abaca fiber made by two different process (soft and severe), the different Young's moduli could be explained by a different fiber adhesion related to different porosities created during the process. It is consistent with the works of Madsen et al. ${ }^{13}$ The importance of the interface between the fibers and the matrix was also demonstrated by a study led by Le Moigne et al. where organosilane treated flax fibers enhanced the Young's modulus from 5.5 GPa to 5.9 GPa. ${ }^{101}$

Works were also conducted with kenaf fibers by Pan et al. ${ }^{\mathbf{1 0 2}}$ They produced a composite made of PLA filled with $30 \mathrm{wt} \%$ of kenaf fibers with a Young's modulus of $5.01 \mathrm{GPa}$. Their process can be qualitatively estimated as soft. Unfortunately we didn't find other works conducted on same material with the detail of the extrusion process, but Avella et al. have done similar composites by a moderate melt blending process (e.g., $180{ }^{\circ} \mathrm{C}$, 32 RPM and 10 min residential time). ${ }^{103}$ Their composite showed a Young's modulus of $5.23 \mathrm{GPa}$ without compatibilization and 5.45 GPa with coupling agent (maleic anhydride and peroxide). A lower temperature and a lower RPM applied with two screws instead of one slightly enhance the tensile properties of such composites, but it also important to consider the length of the fibers used (respectively $3.0 \mathrm{~mm}$ for Pan et al. and $5.1 \mathrm{~mm}$ for Avella et al.).

Gamon et al. have conducted a study on non-treated miscanthus and bamboo fibers incorporated in PLA by twin-screw extruder. ${ }^{\mathbf{1 0 4}}$ The increase of the severity of the process with the increase of the RPM from 100 to 300, did not appear to have any significant impact on the tensile properties (tensile strength and Young's modulus). The feeding zone for PLA was set at $190{ }^{\circ} \mathrm{C}$, but the mixing temperature was done at $165{ }^{\circ} \mathrm{C}$. The increase of the severity of the process, only by increasing the RPM, seems to have a low impact on the mechanical properties in such experimental conditions. An increase of the temperature and/or a treatment of the fibers would have enhanced these properties.

\subsection{PP composites}

Almost $30 \%$ of the studies about PP composites considered in this review have been conducted on PP reinforced with hemp fibers under various process conditions. Ragoubi et al. have studied such composites with short hemp fibers (0.6 $\mathrm{mm}$ to 1.7 $\mathrm{mm}$ ) at different contents between $10 \mathrm{wt} \%$ and $40 \mathrm{wt} \%$ with a soft extrusion process. ${ }^{23}$ They worked with untreated and corona treated fibers. At $20 \mathrm{wt} \%$, they achieved to produce composites reaching a Young's modulus of respectively $1.1 \mathrm{GPa}$ and 1.2 GPa, while their reference of crude PP has a modulus of 0.7 GPa. This is an augmentation of the Young's modulus by roughly $60 \%$ (non treated fibers) and $70 \%$ (treated fibers). Khoathane et al. also used a similar soft process in order to produce composites filled with $8 \mathrm{~mm}$ long hemp fibers, at different contents between $5 \mathrm{wt} \%$ and $30 \mathrm{wt} \%$ in a PP 
compatibilized with 1-pentene. ${ }^{\mathbf{1 0 5}}$ Such polymeric matrix has a Young's modulus of $1.2 \mathrm{GPa}$, while their composite exhibits a Young's modulus of $2.1 \mathrm{GPa}$ at $20 \mathrm{wt} \%$ fiber content that can be considered as an enhancement of $75 \%$. Elkhaoulani et al. made hemp reinforced polypropylene with a severe process $(125$ RPM and $\left.180-200{ }^{\circ} \mathrm{C}\right) .{ }^{34}$ Without an alkaline treatment of the fibers, their composite filled with $20 \mathrm{wt} \%$ of LC fiber exhibits a Young's modulus of $1.5 \mathrm{GPa}$. This is an improvement of $50 \%$ in comparison with their crude PP (1.0 GPa Young's modulus). With the addition of maleated compatibilizer during the process, the same composite has a Young's modulus of $1.8 \mathrm{GPa}$ $(+80 \%)$. Panaitescu et al. made hemp reinforced composites with a similar severe process (120 RPM and $\left.160-170{ }^{\circ} \mathrm{C}\right) .{ }^{\mathbf{1 0 6}}$ They used a maleated compatibilized PP with a Young's modulus of $0.9 \mathrm{GPa}$. With $20 \mathrm{wt} \%$ of non-treated and silane-treated fibers they get a modulus of $1.5 \mathrm{GPa}(+67 \%)$ in both cases. It is interesting to note that in the two studies the results for the maleated-PP reinforced with $20 \mathrm{wt} \%$ of non-treated hemp fibers are quite different (1.8 GPa and 1.5 GPa respectively), even in these two studies the length of the fibers are very comparable (1.4 $\mathrm{mm}$ and $2 \mathrm{~mm}$ respectively). This difference could be explained by the use of alkaline pretreatment used in the study of Elkhaoulani et al. or by the higher temperature used during the process $\left(180-200{ }^{\circ} \mathrm{C}\right.$ versus $\left.160-170{ }^{\circ} \mathrm{C}\right) .^{34}$

Iorga et al. have made some PP composites reinforced with 4 $\mathrm{mm}$ to $6 \mathrm{~mm}$ long hemp fibers with a severe process involving lower screw speed but higher temperature (40 RPM and 190-215 $\left.{ }^{\circ} \mathrm{C}\right) .{ }^{35}$ In comparison with their crude PP reference $(1.8 \mathrm{GPa}$ Young's modulus), their composite reinforced with $25 \mathrm{wt} \%$ of non-treated hemp fiber reaches a modulus of $2.9 \mathrm{GPa}$, which corresponds to an increase of $61 \%$. This increase of the Young's modulus is slightly higher for the composites of Iorga et al. than for Elkhaoulani et al. On one hand, this difference could be explained by the little differences of fiber content (respectively $20 \mathrm{wt} \%$ and $25 \mathrm{wt} \%$ ) and by the length of the fiber (respectively $1.4 \mathrm{~mm}$ and 4 to $6 \mathrm{~mm}$ ). On the other hand, it is also possible to suspect an influence of the process. Even if they are both considered as severe, they exhibit different RPM and temperature profile. The RPM can influence the dispersion and/or shorten the fibers as described by Berzin et $a l^{22}$ or even enhance the porosity as described by Cisneros $e t$ al. ${ }^{90} \mathrm{~A}$ process temperature above $200{ }^{\circ} \mathrm{C}$ can also degrade the fibers, as described by Bogoeva-Gaceva et al. ${ }^{107}$ and by Hanawalt et al. ${ }^{88}$ Nevertheless, the temperature profile used by Iorga et al. ${ }^{35}$ was composed of nine stages and the temperature of $215^{\circ} \mathrm{C}$ was set at the third stage, prior to the incorporation of the fibers, which occurred on the fourth stage. Rachini et al. used a severe process with a high screw speed (400 RPM and $160-170{ }^{\circ} \mathrm{C}$ ) to make hemp reinforced $\mathrm{PP}^{24}$ Unfortunately, we do not have the modulus value for their crude PP for comparison but with 30 wt $\%$ non-treated fiber they achieved to produce a composite exhibiting a modulus of $5.0 \mathrm{GPa}$.

\section{Process impact and control}

Considering the whole world of extrusion, there are many degrees of freedom that are important to consider to correctly prepare composites, like screw profile, screws speed or temperature (Fig. 4).

\subsection{Single and twin-screw extruders}

Single-screw or twin-screw extruders provide very different shearing and mixing conditions during the process. Twin-screw extruders are mostly preferred to achieve good homogeneity of fibers in the composites or nanoparticles in nanocomposites. ${ }^{\mathbf{1 0 8}}$ As it is important to monitor the mechanical energy provided by the screws, in some cases it is important to wisely choose the extrusion process. LC fibers could be very shortened due to mechanical stress in a twin-screw extruders, ${ }^{22,109}$ even with soft conditions (low speed rate of the screws and/or short screw length), while shorts fibers mainly require an homogeneous dispersion level throughout the polymeric matrix. A comparison between single-screw and twin-screw extruders was made by Connelly et al. with a 2D simulation. ${ }^{110}$ They pointed out an improved spreading of particles meaning twin-screw extruder is more suitable for mixing than single-screw extruder.

Although twin-screw extruder has to be preferred to process composites for industrial applications, single-screw extruder should not be neglected for LC fibers composites processing. ${ }^{11,111}$ Single-screw can also be used to reduce the shear rate in order to preserve the cohesiveness of LC fibers for some reasons (e.g., investigation of the pretreatment effectiveness, development of analytical methods). ${ }^{14}$ Choosing between a single-screw or a twin-screw extruder should be the first action to conduct before processing LC fibers reinforced composites and, to our opinion, could be considered as the first parameter to define. Ideally, the choice of the extruder should be solely guided by the applications aimed for the composites (e.g., scientific research, industrial application).

\subsection{Screw profile and speed}

Baiardo et al. have studied the influence of the process conditions on their flax fiber reinforced polyester composites. ${ }^{\mathbf{1 1 2}}$ Their experiments were conducted on a two rotors mixer, at $120{ }^{\circ} \mathrm{C}$ during $5 \mathrm{~min}$ to $15 \mathrm{~min}$, with screw speed set from 10 RPM to 50 RPM. The fiber length, which was initially comprised between 0.25 and $0.9 \mathrm{~mm}$, tends to decrease when the mixing time or the screw speed increases, leading to a decrease of the mechanical properties of the composites. These works were not conducted on an extruder, but they still exhibit interest because Berzin et al. also showed similar results during extrusion processes. ${ }^{22}$ These works were done on PCL reinforced with hemp fibers and processed on a twin-screw extruder set at $100{ }^{\circ} \mathrm{C}$, with screw speed varying from 100 RPM to 300 RPM. The SME were pointed as the main causes for the reduction of the length of the LC fibers. They provided a model allowing the prediction of the evolution of the fiber length along the screw profile. Nevertheless an increase of the aspect ratio of the fibers, due to an increase of the decohesion of the fiber elements during the extrusion process, was reported by Alvarez et al. with sisal fibers starch reinforced composites. ${ }^{\mathbf{1 1 3}}$ These works were conducted on a twin-screw extruder. The mechanical properties were enhanced when the screw speed was increased from 25 to 60 
RPM, then they decreased at a higher speed rate. El-Sabbagh et al. report a reduction of almost $10 \%$ of the diameter of flax fibers incorporated in PP by twin-screw extrusion, and also a shortening of such fibers closely related to the screw profile. ${ }^{57}$ It is important to consider the whole implications of the extrusion process due to mechanical energy transmitted to the LC fiber. There is a need of energy to correctly mix and disperse the fibers throughout the polymeric matrix. It enhances the aspect ratio and leads to composites with increased mechanical properties. Excess of mechanical energy can break the fibers and be detrimental for the mechanical properties. This is consistent with the results described by El-Sabbagh et al. ${ }^{57}$ As a statement, it is very important to correctly set the rotation speed of the screws, in accordance with their length, in order to control the mechanical energy given to these fibers. Software (e.g., Ludovic ${ }^{\circledR}$ ) are very helpful to simulate and to determine the SME in a specific process. ${ }^{2}$

The screw profile is also an important factor to be considered. The screws are composed of elements with various shapes for various uses (e.g., conveying, mixing), as depicted in Fig. 8. The screw profile can be set to modulate the residence time, by using conveyors or reverse elements. The use of reverse screw elements increases the SME and the severity of the process. ${ }^{114}$ It can also increase the shearing with mixing or kneader elements. Lertwimolnun et al. have demonstrated that the screw profile is an important factor to improve the exfoliation of organoclay in PP but not only the one to take into consideration. ${ }^{\mathbf{1 1 5}}$ They also pointed out the ineffectiveness of a too severe profile.

Optimizing the screw speed is an easy way to regulate the flow rate of matter and the production of composites. It should be the second parameter to set since it is directly linked to the speed of the feeders of crude polymer and LC fibers, allowing to adjust the LC fibers content in the final composite. The third parameter, the optimization of the screw profile, is far trickier. It requires high skill and knowledge due to the large amount of possibilities given by the diversity of screw elements. A full set of conveyor elements all along the screws completed with only two small zones of mixing elements, located after the feeder of crude polymer and the feeder of LC fibers (Fig. 8), is often a good system to begin extrusion study.

\subsection{Temperature of the process}

The LC fibers are quite sensitive to thermal degradation. ${ }^{\mathbf{1 1 6}}$ Summerscales et al. indicate a temperature of $200{ }^{\circ} \mathrm{C}$ for the degradation of the cellulose in fibers. ${ }^{117}$ They also pointed out the importance of managing the time/temperature ratio in the decrease of mechanical properties of LC fibers due to thermal degradation. It is consistent with the study of Van de Velde et al. showing that a thermal treatment at $180{ }^{\circ} \mathrm{C}$ during $15 \mathrm{~min}$ degrades flax fibers and led to decreased mechanical properties (e.g., tensile stress and strain). ${ }^{72,118}$ Most of the considered studies in this review exhibit temperatures comprised in a range of $160-190{ }^{\circ} \mathrm{C}$ for PLA, $100-160{ }^{\circ} \mathrm{C}$ for PCL and $160-215{ }^{\circ} \mathrm{C}$ for PP. Amongst the works carried on PP reported in this review, only Iorga et al. have conducted experiments up to $215^{\circ} \mathrm{C}$ and it occurred in a zone of the extruder located prior to the incorporation of the fibers. ${ }^{35}$ Nearly $90 \%$ of the studies considered in this review used a temperature profile comprised between $160{ }^{\circ} \mathrm{C}$ and $200{ }^{\circ} \mathrm{C}$ for PP.

To sum up, most process have a maximum temperature of $200{ }^{\circ} \mathrm{C}$. Nevertheless, to achieve a better dispersion or to optimize a process in accordance with a specific pretreatment of the fibers, it is possible to warm up the polymeric matrix in the first zones of the extruder prior to the incorporation of the fibers in other zones where the temperature is reduced. Such protocol could benefit from the low viscosity of the matrix, and of the mechanical strength given by the screws, to achieve the incorporation of the fibers before the crystallization or before the increase of the viscosity due to the cooling of the polymeric chains.

The temperature of the process is highly dependent of the shear rate as well as the RPM and the screw profile. This is why we believe it should be the fourth parameter to optimize. The setting of the temperature depends on the compromise between the thermal degradation of the LC fibers and the viscosity during the process that has to be optimized. Even with an upholding of the mechanical properties, the degradation of the LC fibers during the process could modify the color or the smell of the final material thus impacting its final applications (especially in industrial sector). Optimizing the process temperature is not as easy as it seems and should not be underestimated, also with regards to the potential organic volatile compounds that might be released.

\subsection{Estimation of the severity of the process}

The severity of the process affects the Young's modulus of the composites reinforced with LC fibers. It is quite obvious to consider that a too soft process could not achieve a good dispersion of the fibers across the matrix, while a too severe process would just degrade the components. The difficulty remains in the optimization of each parameter of the extrusion process to reach the best properties for the final composite. It is also important to note that changing only one parameter could be insufficient to have a significant impact on the final properties of the composites. ${ }^{\mathbf{1 0 4}}$ Moreover, the influence of each parameter depends on the matrix used. As previously discussed for PLA composites, higher Young's moduli are achieved with twin-screw and soft/moderate temperature $\left(160-180{ }^{\circ} \mathrm{C}\right)$ while RPM has a minor influence. PP composites also reach higher Young's modulus with twin-screw extruder and moderate temperature (not exceeding $200{ }^{\circ} \mathrm{C}$ ), but the RPM has a stronger influence than for PLA composites for increasing or decreasing the Young's modulus. In their review, Bogoeva-Gaceca et al. recommend to avoid exceeding $200{ }^{\circ} \mathrm{C}$ and long residential time. ${ }^{107}$ In other words, it is also important to adjust the residential time throughout the optimization of the RPM and of the screw profile in accordance with the length of the screws. Since the enhancement of the screws speed could involve an increase of the mechanical constraint, as described previously, it is quite difficult to set an optimized temperature profile. Considering the publications where it is properly indicated, the length of the LC fibers used in PLA are comprised between $1 \mathrm{~mm}$ and $25 \mathrm{~mm}$ 
( $80 \%$ under $5 \mathrm{~mm}$ ) whereas they are comprised between $0.6 \mathrm{~mm}$ and $55 \mathrm{~mm}(80 \%$ under $5 \mathrm{~mm})$ in PP composites. The alone shortening of the LC fibers during the process is not sufficient to explain the different impact of the RPM with PLA and PP matrixes. It is also possible to consider the affinities between the matrix and the LC fibers as an additional explanation for such differences. This would mean that the optimization of the severity of the process, and especially the setting of the RPM parameter, should probably be done in accordance with the pretreatment of the LC fibers. As the severity of the process is directly related to the whole process parameters - single or twinscrew, screw speed and profile, temperature - operators should seriously consider the benefits of a complete experimental design to achieve a suitable optimization of their process. Software that are dedicated to simulating, optimizing and driving twin-screw extrusion are commercially available. However, very few of them have looked at or even integrated both the impact on the process and the evolution of the LC fibers during the compounding. This is probably the consequence of the complexity of describing LCs, and also the fact that their integration on an industrial scale is relatively recent compared to glass fibers. Nevertheless, for twin-screw extrusion, a pilot module (a first beta version) of LC fibers has just recently been integrated into one of these piloting software, Ludovic®. Others will come on the market most certainly with the expansion of short-fiber thermoplastic composites.

\section{Conclusions}

This review reports on the LC fibers for enhancement of composites properties, centered in the extrusion process. The main conclusions obtained from the literature review point out that:

(i) It seems there is no favored LC fibers used for thermoplastic composites, but short fibers (shorter than $10 \mathrm{~mm}$ ) are the most popular. They are used without any pretreatment or with an alkaline treatment prior extrusion.

(ii) The most used polymeric matrixes are PP and PLA. PP is often the time used with maleic acid (prior or during the extrusion process). PLA is mostly used without any specific compatibilizer.

(iii) Twin-screw extruder seems to be preferred with short fibers to achieve a good dispersion. Single-screw extruder involves a reduced shear rate in comparison with twin-screw and is favored to process composite reinforced with longer fibers.

(iv) The enlargement and improvement of characterization methods of the LC fibers now provide more robust numerical data to conclude on the effect of processing parameters and pretreatments on the aspect ratio of the fibers and on the microstructure of the composites.

(v) The knowledge in setting the experimental parameters of the extruder mostly relay on empiric and operator's experience.

Due to the occurrence of the NFC, regards to the opportunity of valorizing the LC fibers in accordance with the development of the green economy, a large amount of studies are conducted worldwide. Great efforts are made to understand the impact of the process parameters on the aspect ratio of the fibers, on the fiber/matrix interfaces, on the composites microstructure and on the final properties of the materials. Our opinion about the close future is that we are convinced that a more theoretical approach for simulating the extrusion process conditions will bring new knowledge for the optimization of the experimental parameters in combination with proper designs of experiments. Adding the SME in the experimental section of studies in the future should dramatically help the rationalization of the extrusion process. In such outlook, experimental design would be a perfect tool to help optimizing the process parameters and to achieve such rationalization.

Although the aspect ratio and the dispersion of the LC fibers are mainly improved through the optimization of the process parameters, the compatibility between the LC fibers and the polymeric matrix as well as the porosity are mostly dependent on the pretreatment of the LC fibers. Numerous studies are conducted to design new pretreatment methods, but alkaline treatments seem to be the most common and effective ones. Nevertheless, the pretreatment of the LC fibers and the optimization of the process parameters are strongly interdependent. Reactive extrusion could be a serious alternative to this two-step process by optimizing both microstructure and interface in a single-step process.

The properties of the feasible composites reinforced with LC fibers are still limited by the chemical and the physical properties of the polymeric matrices themselves. The optimization of the process parameters, and especially the cumulative strain and the SME, ${ }^{119}$ is dependent on the properties of the polymeric matrix (e.g., melting temperature, viscosity). Creating new thermoplastic polymers - preferably biobased polymers - could be a relevant alternative to improve the interface between LC fibers and the polymeric matrix. Designing polymers with decreased melting temperature or adaptable viscosity could also be a promising way to reduce the SME during the process of the composites.

\section{Conflict of interest}

There are no conflicts of interest to declare.

\section{Acknowledgements}

The Fondation de France site Paris-Reims is gratefully acknowledged for supporting the grant of Dr Antoine Gallos and the ANS ' $\mu$ Reshape' funding support received from the department Science for Food and Bioproduct Engineering of INRA in the frame of the FEDERATIF project. The authors also thank the French national research Network GDR 3710 INRA/ CNRS SYMBIOSE - Synthons et matériaux biosourcés, for its support. This work was funded by The Fondation de France site Paris-Reims.

\section{References}

1 Z. Hashin, J. Appl. Mech., 1983, 50, 481-505. 
2 J. Beaugrand and F. Berzin, J. Appl. Polym. Sci., 2013, 128, 1227-1238.

3 OECD/FAO, OECD-FAO Guidance for Responsible Agricultural Supply Chains, OECD Publishing, Paris, 2013.

4 J. Potts, M. Lynch, A. Wilkings, G. Huppé, M. Cunningham and V. Voora, State of Sustainability Initiatives Review, 2014.

5 M. Carus, A. Eder, L. Dammer, H. Korte, L. Scholz, R. Essel, E. Breitmayer and M. Barth, Wood-Plastic Composites (WPC) and Natural Fibre Composites (NFC): European and Global Markets 2012 and Future Trends in Automotive and Construction, 2015, vol. 4.

6 European Institute of Innovation \& Technology, EIT's 2016 Call for Knowledge and Innovation Communities (KIC) Proposals, 2016.

7 A. Le Duigou and C. Baley, J. Cleaner Prod., 2014, 83, 61-69. 8 Y. Deng and Y. Tian, Sustainability, 2015, 7, 11462-11483.

9 N. Le Moigne, M. Van Den Oever and T. Budtova, Composites, Part A, 2011, 42, 1542-1550.

10 C. Quijano-Solis, N. Yan and S. Y. Zhang, Composites, Part A, 2009, 40, 351-358.

11 K. L. Pickering, M. G. A. Efendy and T. M. Le, Composites, Part A, 2016, 83, 98-112.

12 K. Oksman, Y. Aitomäki, A. P. Mathew, G. Siqueira, Q. Zhou, S. Butylina, S. Tanpichai, X. Zhou and S. Hooshmand, Composites, Part A, 2016, 83, 2-18.

13 B. Madsen, A. Thygesen and H. Lilholt, Compos. Sci. Technol., 2009, 69, 1057-1069.

14 A. Gallos, G. Paës, D. Legland, F. Allais and J. Beaugrand, Composites, Part A, 2017, 94, 32-40.

15 T. Chou and A. Kelly, Annu. Rev. Mater. Sci., 1980, 10, 229259.

16 Y. Takao, T. W. Chou and M. Taya, J. Appl. Mech., 1982, 49, 536-540.

17 P. A. M. Claassen, J. B. Van Lier, A. M. Lopez Contreras, E. W. J. Van Niel, L. Sijtsma, A. J. M. Stams, S. S. De Vries and R. A. Weusthuis, Appl. Microbiol. Biotechnol., 1999, 52, 741-755.

18 T. Mukherjee and N. Kao, J. Polym. Environ., 2011, 19, 714725.

19 T. A. Hottle, M. M. Bilec and A. E. Landis, Polym. Degrad. Stab., 2013, 98, 1898-1907.

20 D. U. Shah, Mater. Des., 2014, 62, 21-31.

21 D. U. Shah, R. K. Nag and M. J. Clifford, Cellulose, 2016, 23, 1481-1490.

22 F. Berzin, B. Vergnes and J. Beaugrand, Composites, Part A, 2014, 59, 30-36.

23 M. Ragoubi, D. Bienaimé, S. Molina, B. George and A. Merlin, Ind. Crops Prod., 2010, 31, 344-349.

24 A. Rachini, G. Mougin, S. Delalande, J.-Y. Charmeau, C. Barrès and E. Fleury, Polym. Degrad. Stab., 2012, 97, 1988-1995.

25 X. Li, R. Xiao, J. J. Morrell, X. Zhou and G. Du, Ind. Crops Prod., 2017, 97, 465-468.

26 M. A. Sawpan, K. L. Pickering and A. Fernyhough, Composites, Part A, 2011, 42, 310-319.

27 M. A. Sawpan, K. L. Pickering and A. Fernyhough, Composites, Part A, 2011, 42, 1189-1196.
28 K. L. Pickering, M. A. Sawpan, J. Jayaraman and A. Fernyhough, Composites, Part A, 2011, 42, 1148-1156.

29 M. A. Sawpan, K. L. Pickering and A. Fernyhough, Composites, Part A, 2012, 43, 519-526.

30 G. W. Beckermann and K. L. Pickering, Composites, Part A, 2009, 40, 210-217.

31 S. Oza, H. Ning, I. Ferguson and N. Lu, Composites, Part B, 2014, 67, 227-232.

32 T. L. Bayush, B. Thattai, S. Pillay and U. Vaidya, in ECCM1515th European Conference on Composite Materials, 2012.

33 M. Mihai and J. Denault, in Annual Technical Conference ANTEC, 2011, vol. 2, pp. 1014-1019.

34 A. Elkhaoulani, F. Z. Arrakhiz, K. Benmoussa, R. Bouhfid and A. Qaiss, Mater. Des., 2013, 49, 203-208.

35 M. D. Iorga, Z. Vuluga, M. Dan, A. N. Frone, D. Florea and D. M. Panaitescu, Mater. Plast., 2013, 50, 296-299.

36 European Commission of Linen and Hemp, Barometer of European flax 2015, 2015.

37 M. Karus and D. Vogt, Euphytica, 2004, 140, 7-12.

38 R. Johnson, Hemp as an Agricultural Commodity, 2015.

39 M. Carus, L. Dammer, L. Scholz, R. Essel and E. Breitmayer, Bioplastics Mag., 2012, 9, 42-44.

40 S. V. Joshi, L. T. Drzal, A. K. Mohanty and S. Arora, Composites, Part A, 2004, 35, 371-376.

41 R. H. Mills, D. J. Gardner and R. Wimmer, J. Appl. Polym. Sci., 2008, 110, 3880-3888.

42 A. Mader, A. Kondor, T. Schmid, R. Einsiedel and J. Müssig, Compos. Sci. Technol., 2016, 123, 163-170.

43 A. Bourmaud, D. Akesson, J. Beaugrand, A. Le Duigou, M. Skrifvars and C. Baley, Polym. Degrad. Stab., 2016, 128, 77-88.

44 S. E. Selke and I. Wichman, Composites, Part A, 2004, 35, 321-326.

45 C. R. Di Franco, V. P. Cyras, J. P. Busalmen, R. A. Ruseckaite and A. Vázquez, Polym. Degrad. Stab., 2004, 86, 95-103.

46 I. Šimkovic, in Polymer Degradation and Stability Research Developments, ed. L. B. Albertov, Nova Science Publishers, Inc, 2007, pp. 217-236.

47 S. Kalia, K. Thakur, A. Celli, M. A. Kiechel and C. L. Schauer, J. Environ. Chem. Eng., 2013, 1, 97-112.

48 K. L. Pickering, Properties and performance of natural-fibre composites, Elsevier, 2008.

49 M. M. Kabir, H. Wang, K. T. Lau and F. Cardona, Composites, Part B, 2012, 43, 2883-2892.

50 O. Faruk, A. K. Bledzki, H. Fink and M. Sain, Prog. Polym. Sci., 2012, 37, 1552-1596.

51 A. K. Bledzki, A. A. Mamun, A. Jaszkiewicz and K. Erdmann, Compos. Sci. Technol., 2010, 70, 854-860.

52 O. Faruk and M. Sain, Biofiber reinforcements in composite materials, Elsevier, 2014.

53 R. Bag, J. Beaugrand, P. Dole and B. Kurek, Holzforschung, 2011, 65, 239-247.

54 J. Bouajila, A. Limare, C. Joly and P. Dole, Polym. Eng. Sci., 2005, 45, 809-816.

55 X. Li, L. G. Tabil and S. Panigrahi, J. Polym. Environ., 2007, 15, 25-33. 
56 H.-S. Kim, B.-H. Lee, S.-W. Choi, S. Kim and H.-J. Kim, Composites, Part A, 2007, 38, 1473-1482.

57 A. M. M. El-Sabbagh, L. Steuernagel, D. Meiners and G. Ziegmann, J. Appl. Polym. Sci., 2014, 131, 1-15.

58 N. Hamour, A. Boukerrou, H. Djidjelli, J.-E. Maigret and J. Beaugrand, Int. J. Polym. Sci., 2015, 2015, 1-9.

59 D. Puglia, A. Terenzi, S. E. Barbosa, J. M. Kenny and M. Kenny, Compos. Interfaces, 2008, 15, 111-129.

60 Y. Li, Y. W. Mai and L. Ye, Compos. Sci. Technol., 2000, 60, 2037-2055.

61 S. Mishra, A. K. Mohanty, L. T. Drzal, M. Misra, S. Parija, S. Nayak and S. S. Tripathy, Compos. Sci. Technol., 2003, 63, 1377-1385.

62 J.-L. Wertz, J. P. Mercier and O. Bédué, Cellulose science and technology, CRC Press, 2010.

63 V. Vandenbossche, J. Brault, G. Vilarem, O. HernándezMeléndez, E. Vivaldo-Lima, M. Hernández-Luna, E. Barzana, A. Duque, P. Manzanares, M. Ballesteros, J. Mata, E. Castellón and L. Rigal, Ind. Crops Prod., 2014, 55, 258-266.

64 C. Stevens and J. Müssig, Industrial applications of natural fibres: structure, properties and technical applications, John Wiley \& Sons, 2010, vol. 10.

65 K. Haag, J. Padovani, S. Fita, J.-P. Trouvé, C. Pineau, S. Hawkins, H. De Jong, M. K. Deyholos, B. Chabbert, J. Müssig and J. Beaugrand, Ind. Crops Prod., 2017, 98, 1-9.

66 S. Fita, I. Roig and O. Menes, JEC Compos. Mag., 2015, 101, 25-28.

67 D. Hardy, A. Rogeon and M. Boutin, JEC Compos. Mag., 2015, 101, 52-53.

68 C. Williams, J. Summerscales and S. Grove, Composites, Part A, 1996, 27, 517-524.

69 A. Fina, D. Tabuani, A. Frache and G. Camino, Polymer, 2005, 46, 7855-7866.

70 W. Liu, L. T. Drzal, A. K. Mohanty and M. Misra, Composites, Part B, 2007, 38, 352-359.

71 S. R. Dhakate, R. B. Mathur, B. K. Kakati and T. L. Dhami, Int. J. Hydrogen Energy, 2007, 32, 4537-4543.

72 K. Van De Velde and P. Kiekens, Compos. Struct., 2001, 54, 355-360.

73 A. Soroudi and I. Jakubowicz, Eur. Polym. J., 2013, 49, 28392858.

74 A. Bourmaud and C. Baley, Polym. Degrad. Stab., 2007, 92, 1034-1045.

75 D. S. Achilias, C. Roupakias, P. Megalokonomos, A. A. Lappas and E. V. Antonakou, J. Hazard. Mater., 2007, 149, 536-542.

76 S. C. Cardona and A. Corma, Appl. Catal., B, 2000, 25, 151162.

77 S. M. Al-Salem, P. Lettieri and J. Baeyens, Waste Manage., 2009, 29, 2625-2643.

78 M. Rask, B. Madsen, B. F. Sørensen, J. L. Fife, K. Martyniuk and E. M. Lauridsen, Composites, Part A, 2012, 43, 16391649.

79 A. Abdennadher, PhD. thesis, MINES ParisTech, Sophia Antipolis, 2015.
80 A. F. Reano, S. Domenek, M. Pernes, J. Beaugrand and F. Allais, ACS Sustainable Chem. Eng., 2016, 4, 6562-6571.

81 R. Castellani, E. Di Giuseppe, J. Beaugrand, S. Dobosz, F. Berzin, B. Vergnes and T. Budtova, Composites, Part A, 2016, 91, 229-237.

82 J. Holbery and D. Houston, J. Miner. Met. Mater. Soc., 2006, 58, 80-86.

83 H. Ku, H. Wang, N. Pattarachaiyakoop and M. Trada, Composites, Part B, 2011, 42, 856-873.

84 H. L. Bos, J. Müssig and M. J. A. Van Den Oever, Composites, Part A, 2006, 37, 1591-1604.

85 M. Maniruzzaman, J. S. Boateng, M. J. Snowden and D. Douroumis, ISRN Pharm., 2012, 2012, 436763-436769.

86 D. V. Rosato, Extruding plastics: a practical processing handbook, Springer Science \& Business Media, 2013.

87 L. Teuber, H. Militz and A. Krause, Composites, Part A, 2016, 84, 464-471.

88 K. Hanawalt, Plast. Addit. Compd., 2002, 4, 22-25.

89 D. U. Shah, Composites, Part A, 2016, 83, 160-168.

90 F. H. Cisneros and J. L. Kokini, J. Food Eng., 2002, 51, 139149.

91 F. Inceoglu, J. Ville, N. Ghamri, J. L. Pradel, A. Durin, R. Valette and B. Vergnes, Polym. Compos., 2011, 32, 1842-1850.

92 A. K. Bledzki, A. Jaszkiewicz and D. Scherzer, Composites, Part A, 2009, 40, 404-412.

93 D. N. Saheb, J. P. Jog, D. Nabi Saheb and J. P. Jog, Adv. Polym. Technol., 1999, 18, 351-363.

94 A. Amash and P. Zugenmaier, Polym. Bull., 1998, 40, 251258.

95 A. Awal, S. B. Ghosh and M. Sain, J. Therm. Anal. Calorim., 2010, 99, 695-701.

96 J. Alongi, Z. Han and S. Bourbigot, Prog. Polym. Sci., 2015, 51, 28-73.

97 S. Bourbigot and G. Fontaine, Polym. Chem., 2010, 1, 1413. 98 M. M. Thwe and K. Liao, Composites, Part A, 2002, 33, 43-52.

99 M. M. Thwe and K. Liao, Compos. Sci. Technol., 2003, 63, 375-387.

100 A. K. Bledzki and A. Jaszkiewicz, Compos. Sci. Technol., 2010, 70, 1687-1696.

101 N. Le Moigne, M. Longerey, J.-M. Taulemesse, J.-C. Bénézet and A. Bergeret, Ind. Crops Prod., 2014, 52, 481-494.

102 P. Pan, B. Zhu, W. Kai, S. Serizawa, M. Iji and Y. Inoue, J. Appl. Polym. Sci., 2007, 105, 1511-1520.

103 M. Avella, G. Bogoeva-Gaceva, A. Bužarovska, M. E. Errico, G. Gentile and A. Grozdanov, J. Appl. Polym. Sci., 2008, 108, 3542-3551.

104 G. Gamon, P. Evon and L. Rigal, Ind. Crops Prod., 2013, 46, 173-185.

105 M. C. Khoathane, O. C. Vorster and E. R. Sadiku, J. Reinf. Plast. Compos., 2008, 27, 1533-1544.

106 D. M. Panaitescu, Z. Vuluga, M. Ghiurea, M. Iorga, C. Nicolae and R. Gabor, Composites, Part B, 2015, 69, 286-295.

107 G. Bogoeva-Gaceva, M. Avella, M. Malinconico, A. Buzarovska, A. Grozdanov, G. Gentile and M. E. Errico, Polym. Compos., 2007, 28, 98-107. 
108 M. A. Treece and J. P. Oberhauser, J. Appl. Polym. Sci., 2007, 103, 884-892.

109 F. Berzin, T. Amornsakchai, A. Lemaitre, E. Di Giuseppe and B. Vergnes, Polym. Compos., DOI: 10.1002/pc.24475.

110 R. K. Connelly and J. L. Kokini, J. Food Eng., 2007, 79, 956969.

111 R. Malkapuram, V. Kumar and Y. S. Negi, J. Reinf. Plast. Compos., 2009, 28, 1169-1189.

112 M. Baiardo, E. Zini and M. Scandola, Composites, Part A, 2004, 35, 703-710.

113 V. Alvarez, A. Iannoni, J. M. Kenny and A. Vasquez, J. Compos. Mater., 2005, 39, 2023-2038.

114 B. K. Gogoi, A. J. Oswalt and G. S. Choudhury, J. Food Sci., 1996, 61, 590-595.

115 W. Lertwimolnun and B. Vergnes, Polym. Eng. Sci., 2007, 47, 2100-2109.

116 H. Yang, R. Yan, H. Chen, D. H. Lee and C. Zheng, Fuel, 2007, 86, 1781-1788.

117 N. P. Summerscales, J. Dissanayake, A. S. Virk and W. Hall, Composites, Part A, 2010, 41, 1329-1335.

118 A. Bourmaud, A. Le Duigou, C. Gourier and C. Baley, Ind. Crops Prod., 2016, 84, 151-165.

119 E. Di Giuseppe, R. Castellani, T. Budtova and B. Vergnes, Composites, Part A, 2017, 95, 31-39.

120 M. Ragoubi, B. George, S. Molina, D. Bienaimé, A. Merlin, J. M. Hiver and A. Dahoun, Composites, Part A, 2012, 43, 675-685.

121 A. Bourmaud, Y.-M. Corre and C. Baley, Ind. Crops Prod., 2015, 64, 251-257.

122 A. Bourmaud and C. Baley, Polym. Degrad. Stab., 2010, 95, 1488-1494.
123 V. B. Carmona, A. de Campos, J. M. Marconcini and L. H. C. Mattoso, J. Therm. Anal. Calorim., 2014, 115, 153160.

124 A. K. Bledzki, P. Franciszczak, Z. Osman and M. Elbadawi, Ind. Crops Prod., 2015, 70, 91-99.

125 D. Paukszta, Fibres Text., 2005, 13, 107-109.

126 F. Z. Arrakhiz, M. Malha, R. Bouhfid, K. Benmoussa and A. Qaiss, Composites, Part B, 2013, 47, 35-41.

127 F. E. El-Abbassi, M. Assarar, R. Ayad and N. Lamdouar, Compos. Struct., 2015, 133, 451-457.

128 A. Retegi, A. Arbelaiz, P. Alvarez, R. Llano-Ponte, J. Labidi and I. Mondragon, J. Appl. Polym. Sci., 2006, 102, 34383445.

129 M. D. F. V. Marques, R. P. Melo, R. D. S. Araujo, J. D. N. Lunz and V. D. O. Aguiar, J. Appl. Polym. Sci., 2015, 132, 1-12.

130 G. Ausias, A. Bourmaud, G. Coroller and C. Baley, Polym. Degrad. Stab., 2013, 98, 1216-1224.

131 A. S. Doumbia, M. Castro, D. Jouannet, A. Kervoëlen, T. Falher, L. Cauret and A. Bourmaud, Mater. Des., 2015, 87, 331-341.

132 A. El-Sabbagh, L. Steuernagel and G. Ziegmann, Composites, Part B, 2013, 45, 1164-1172.

133 F. Z. Arrakhiz, M. El Achaby, K. Benmoussa, R. Bouhfid, E. M. Essassi and A. Qaiss, Mater. Des., 2012, 40, 528-535.

134 T. T. L. Doan, S. L. Gao and E. Mäder, Compos. Sci. Technol., 2006, 66, 952-963.

135 A. Kabir, M. Huque, R. Islam and A. K. Bledzki, BioResources, 2010, 5, 1618-1625.

136 B. Mano, J. R. Araújo, M. A. S. Spinacé and M.-A. De Paoli, Compos. Sci. Technol., 2010, 70, 29-35.

137 M. T. B. Pimenta, A. J. F. Carvalho, F. Vilaseca, J. Girones, J. P. López, P. Mutjé and A. A. S. Curvelo, J. Polym. Environ., 2008, 16, 35-39. 